\title{
HTP Nutraceutical Screening for Histone Deacetylase Inhibitors and Effects of HDACis on Tumor-suppressing miRNAs by Trichostatin A and Grapeseed (Vitis vinifera) in HeLa cells
}

\author{
ELIZABETH A. MAZZIO and KARAM F.A. SOLIMAN
}

\author{
College of Pharmacy and Pharmaceutical Sciences, Florida A\&M University, Tallahassee, FL, U.S.A.
}

\begin{abstract}
Background/Aim: Aggressive tumor malignancies are a consequence of delayed diagnosis, epigenetic/phenotype changes and chemo-radiation resistance. Histone deacetylases (HDACs) are a major epigenetic regulator of transcriptional repression, which are highly overexpressed in advanced malignancy. While original chemotherapy drugs were modeled after phytochemicals elucidated by botanical screenings, HDAC inhibitors (HDACi) such as apicidin, trichostatin A (TSA) and butyrate were discovered as products of fungus and microbes, in particular, gut microbiota. Therefore, a persistent question remains as to the inherent existence of HDACis in raw undigested dietary plant material. In this study, we conduct a high-throughput (HTP) screening of $\sim 1,600$ non-fermented commonly used nutraceuticals (spices, herbs, teas, vegetables, fruits, seeds, rinds etc.) at $(<600 \mu \mathrm{g} / \mathrm{ml})$ and food-based polyphenolics $(<240 \mu \mathrm{g} / \mathrm{ml})$ for evidence of HDAC activity inhibition in nuclear HeLa cell lysates. Materials and Methods: Human HDAC kinetic validation was performed using a standard fluorometric activity assay, followed by an enzymatic-linked immuno-captured ELISA. Both methods were verified using HDACi panel drugs: TSA, apicidin, suberohydroxamic acid, M344, CL-994, valproic acid and sodium phenylbutyrate. The HTP screening was then conducted, followed by a study comparing biological effects of HDACis in HeLa cells, including analysis of whole-transcriptome non-coding RNAs using Affymetrix miRNA 4.1-panel arrays. Results: The HTP
\end{abstract}

This article is freely accessible online.

Correspondence to: Karam F.A. Soliman, Ph.D., Distinguished Professor, College of Pharmacy \& Pharmaceutical Sciences, Florida A\&M University, Room 104 Dyson Pharmacy Building, 1520 ML King Blvd, Tallahassee, FL 32307, U.S.A. Tel: +1 8505993306, Fax: +1 8505993667, e-mail: karam.soliman@famu.edu

Key Words: Screening, HDAC, grapeseed, miRNA, TSA, HeLa cells. screening results confirmed $44 / 1600$ as potential HDACis to which 31 were further eliminated as false-positives. Methodological challenges/concerns are addressed regarding plant product false-positives that arise from the signal reduction of commercial lysine development reagents. Only $13 \mathrm{HDACis}$ were found having an $\mathrm{IC}_{50}$ under $<200 \mu \mathrm{g} / \mathrm{ml}$ : Grapeseed extract (Vitis vinifera), Great burnet root (Sanguisorba Officinalis), Babul (Acacia arabica), Chinese gallnut (Melaphis chinensis), Konaberry extract (Coffea arabica), Uva Ursi (Arctostaphylos uva ursi), Green tea (Camellia sinensis), Meadowsweet (Filipendula ulmaria), Sassafras (Sassafras officinale), Turkey rhubarb (Rheum palmatum), epigallocatechin gallate (EGCG), gossypol and gallic acid. Next, we investigate the biological consequence of HDACi panel drugs in HeLa cells, where the data suggest predominant effects are anti-mitotic rather than cytotoxic. Lastly, differential effects of TSA vs. GSE at sub-lethal concentrations tested on HeLa cells show 6,631 miRNAs expressed in resting cells, 35 significantly up-regulated (TSA) and 81 up-regulated (GSE), with several miRNAs overlapping in the upward direction by both GSE and TSA (e.g. hsa-miR23b-5p, hsa-miR-27b-5p, hsa-miR-1180-3p, hsa-miR-6880-5p and hsa-mir-943). Using DIANA miRNA online tools, it was determined that GSE and TSA simultaneously cause overexpression of similar miRNAs predicted to destroy the following influential oncogenes: NFkB, NRAS, KRAS, HRAS, MYC, TGFBR1, E2F1, E2F2, BCL21, CDKN1A, CDK6, HIFla, and VEGFA. Conclusion: The data from this study show that plant- based HDACis are relatively rare, and can elicit a similar pattern to TSA in up-regulating miRNAs involved with tumor suppression of HeLa cervical carcinoma.

The term "epigenetics" encompasses a complex multicomponent regulatory system which controls long term and transient changes in gene expression/silencing (1). Histone deacetylases (HDACs) are regulators of transcriptional repression where they catalytically cleave/remove acetyl groups from the epsilon lysine residues on histone tails, creating a net positive charge and greater affinity for negatively 
charged phosphate groups on DNA. This mechanical interaction enables histone/nucleosome constriction and silencing of genes into compact-organized heterochromatin. As technology evolves, so does the classification of HDACS, which are known to include the following: zinc-dependent HDACs include HDACs1 (2, 3 and 8); Class II (4-7, 9, 10), Class IV (11) and nicotinamide regulated HDACs comprising Class III, Sirtuins.

Elevated expression of HDACs are evident in advanced malignancy, where inhibitors (HDACis) antagonize tumor growth $(2,3)$ antagonize tumor growth $(2,3)$, augment chemotherapy (4-7), reverse chemoresistance $(3,8,9)$, attenuate metastasis, halt epithelial-mesenchymal transition (10-12) and block tumor immune evasion $(13,14)$. With the overwhelming surge of HDACis being sought worldwide for nearly every type of cancer (e.g. ovarian (15) neuroblastoma (16) pancreatic (17) liver (18) colon (19) and cervical cancer (20)), a database (HDACiDB) has been established to accommodate this wealth of information. (21) Several mechanisms have been discovered as to how HDACis carry out their anti-tumor effects, including a re-expression of tumor suppressors (e.g. p21, p27 BAX) (22, 23), downregulation of oncogenes (e.g. TGF-beta1, MMP-1 and MMP2 (24), survivin, beta-catenin, N-cadherin and vimentin) (25) and blocking tumor signaling processes (e.g. SMAD4, PI3K, $\mathrm{PI} 3 \mathrm{~K} / \mathrm{AKT} / \mathrm{mTOR})$ (26-28). With advances in epigenetic technologies, many HDAC inhibitors have been documented to alter tumor suppressor miRNAs and thereby influence the growth of cancer $(19,29)$. Given that HDACis were first discovered as products of microorganisms including gut microflora from dietary fiber (30) and HDACi drug development continues to be modeled after microbial metabolites such as trans-cinnamic acid, FK228, YM753 (spiruchostatin A) (31-33), there remains a question as to if HDACis exist in undigested plant materials. In this study, we conduct a high throughput screening of $\sim 1,600$ commonly used nutraceuticals (plants, vegetables, fruits, herbs, vitamins etc.) and polyphenolics for the ability to inhibit HDAC enzymatic activity in HeLa nuclear lysates using a common fluorometric assay. We discuss methodological issues, confirm/validate HDACis using specific product linked ELISAs and then evaluate related epigenetic/biological consequences of two specific HDACis of diverse origin: trichostatin A (TSA) microbial $v s$. a plant based HDACi: grapeseed extract (GSE).

\section{Materials and Methods}

Hanks Balanced Salt Solution, (4-(2-hydroxyethyl)-1piperazineethanesulfonic acid) (HEPES), ethanol, 96 well plates, general reagents and supplies, RNA extraction supplies were all purchased from Sigma-Aldrich (St. Louis, MO, USA) or VWR (Radnor, PA, USA). All microarray reagents and supplies were purchased from Affymetrix (Santa Clara, CA, USA) and natural products were purchased from Frontier Natural Products Co-op (Norway, IA, USA), Monterey Bay Spice Co (Watsonville, CA, USA), Mountain Rose Herbs (Eugene, OR, USA), Mayway Traditional Chinese Herbs (Oakland, CA, USA), Kalyx Natural Marketplace (Camden, NY, USA), a local organic fruit and vegetable market (New Leaf, Tallahassee, FL,USA), Florida Food Products Inc. (Eustis, FL,USA), Konaberry extract from Amazon Rainforest Inc, (Ledgewood NJ, USA) or Patel Brothers Indian Grocery (Tampa, FL, USA). Grapeseed Extracts were purchased from Hard Eight Nutrition LLC (Henderson, NV,USA), Futureceuticals (Momence, IL,USA), and from capsules obtained at General Nutrition Center (GNC) and Swanson Health Products (Fargo, ND, USA). HDAC activity assays were purchased from Abcam (Cambridge, MA, USA), Enzo Life Sciences through VWR (Radnor, PA, USA) and Epigentek (Farmingdale, NY, USA).

Cell culture. HeLa (ATCC ${ }^{\circledR}$ CCL-2 ${ }^{\mathrm{TM}}$ ) cells were purchased from the American Type Culture Collection (Manassas, VA, USA). Cells were cultured in DMEM high glucose media [glucose $4,500 \mathrm{mg} / \mathrm{L}$ ] containing 5\% FBS, $4 \mathrm{mM} \mathrm{L}$-glutamine, and penicillin/streptomycin $(100 \mathrm{U} / 0.1 \mathrm{mg} / \mathrm{ml})$. Culture conditions were maintained at $37^{\circ} \mathrm{C}$ in $5 \%$ $\mathrm{CO}_{2}$ /atmosphere and every 2-3 days, the media was replaced and cells sub-cultured, and culture media was used for all in vitro experiments.

Herbal, compound and drug preparations. All natural chemicals and reference drugs were dissolved in dimethylsulfoxide (DMSO) $[5-20 \mathrm{mg} / \mathrm{mL}]$, and crude herbs were prepared in absolute ethanol [50 $\mathrm{mg} / \mathrm{ml}]$ after being diced, macerated and powdered, all stored at $-20^{\circ} \mathrm{C}$. Serial dilutions were prepared in sterile HBSS $+5 \mathrm{mM}$ HEPES, adjusted to a $\mathrm{pH}$ of 7.4 and solvent concentration of DMSO or absolute ethanol was maintained at less than $0.5 \%$ for all experiments.

Cell viability. Cell viability and cell counts were quantified using resazurin [7-Hydroxy-3H-phenoxazin-3-one 10-oxide] (Alamar Blue) indicator dye (34). A working solution of resazurin was prepared in sterile HBSS minus phenol red $(0.5 \mathrm{mg} / \mathrm{ml})$, and then added $(15 \%$ $\mathrm{v} / \mathrm{v}$ ) to each sample. Samples were returned to the incubator for 2-4 $\mathrm{h}$ and reduction of the dye by viable cells (to resorufin, a fluorescent compound) was quantitatively analyzed using a Synergy HTX multimode reader (Bio-Tek, Winooski, VT, USA) with settings at [550/580], [excitation/emission]. For toxicity studies, HeLa cells were placed in growth media at a cell density of $0.5 \times 10^{5}$ cells $/ \mathrm{ml}$ in 96 well plates and viability assessed at $24 \mathrm{~h}$ of incubation. For cell proliferation, HeLa cells were placed in growth media at a cell density of $0.04 \times 10^{5}$ cells $/ \mathrm{ml}$ in 96 -well plates and viability was assessed at 3-4 days incubation, using paclitaxel as a negative control.

HDAC activity. An HDAC activity assay [ab156064] Abcam (Cambridge, MA, USA) was used for high-throughput screening of natural products, being conducted in accordance with the manufacturers guidelines. A pre-read and subsequent post-read was acquired using a Synergy HTX Multi-Mode Reader Excitation: 355/40, Emission: 460/40, optics: Top, Gain: 37. Solvent controls were used to detect and account for product/developer signal decay and compared to the full enzyme reactant samples. Data was acquired using Gen5 ${ }^{\text {TM }}$ Data Analysis Software 2.06.10.

An ELISA based HDAC Activity /Inhibition direct assay \# P4035 (Epigentek Group Inc. Farmingdale, NY, USA) was used for dual detection validation. This product has major advantages in that 


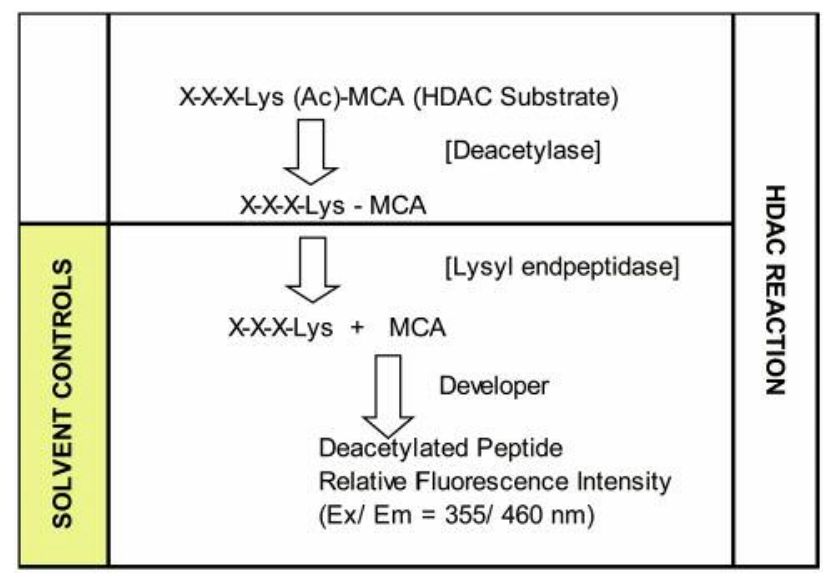

Figure 1. HDAC activity assay layout. HDAC substrate is cleaved and then detected by a developer reaction solution containing lysyl endopeptidase. Determination of HDAC activity=Enzyme $+\mathrm{TX}+$ Developer/Assay Solution - TX+ No Enzyme + Developer/Assay Solution [Solvent Control].

the substrate is bound to microplate wells, the enzyme converts the bound substrate to a product, and after several washes - the product is detected by ELISA. The assay was conducted according to the manufacturer's protocol, samples read on a Synergy HTX MultiMode Reader and data acquired using Gen5 ${ }^{\mathrm{TM}}$ Data Analysis Software 2.06.10

Genomic profiling of TSA vs. Grapeseed extract. miRNA profiling was accomplished using a FlashTag ${ }^{\mathrm{TM}}$ Biotin HSR RNA Labeling Kit on RNA spiked with oligo controls. Briefly, RNA was isolated, purified and quantified, spiked, diluted in ATP/Poly A Tail Master Mix and incubated a $37^{\circ} \mathrm{C}$ heat block for $15 \mathrm{~min}$. Flash Tag Biotin HSR ligation mix was added with T4 DNA ligase and incubated at RT for $30 \mathrm{~min}$. The reaction was stopped, and a QC assay was run. The sample was hybridized to an Affymetrix array strip at $48^{\circ} \mathrm{C}$ and added to a hybridization cocktail. Samples were denatured at $95^{\circ} \mathrm{C}$ (thermocycler plates) for $5 \mathrm{~min}$, followed by $45^{\circ} \mathrm{C}$ for $5 \mathrm{~min}$. Samples were analyzed using Affymetrix gene atlas software and analyzed by DIANA (35).

Docking and data analysis. Statistical analysis was performed using Graph Pad Prism (version 3.0; Graph Pad Software Inc. San Diego, CA, USA) with the significance of the difference between the groups assessed using a one-way ANOVA, followed by Tukey post hoc means comparison test or a 2-way ANOVA. $\mathrm{IC}_{50} \mathrm{~s}$ were determined by regression analysis using Origin Software (OriginLab, Northampton, MA). Molecular docking of active polyphenolics to the known structure of human HDAC2 was conducted using lead optimization software - Mcule, Inc. (Palo Alto, CA, USA).

\section{Results}

Method validation and study setup. A series of method validation studies were first performed on human HDAC nuclear lysates to determine activity by product formation

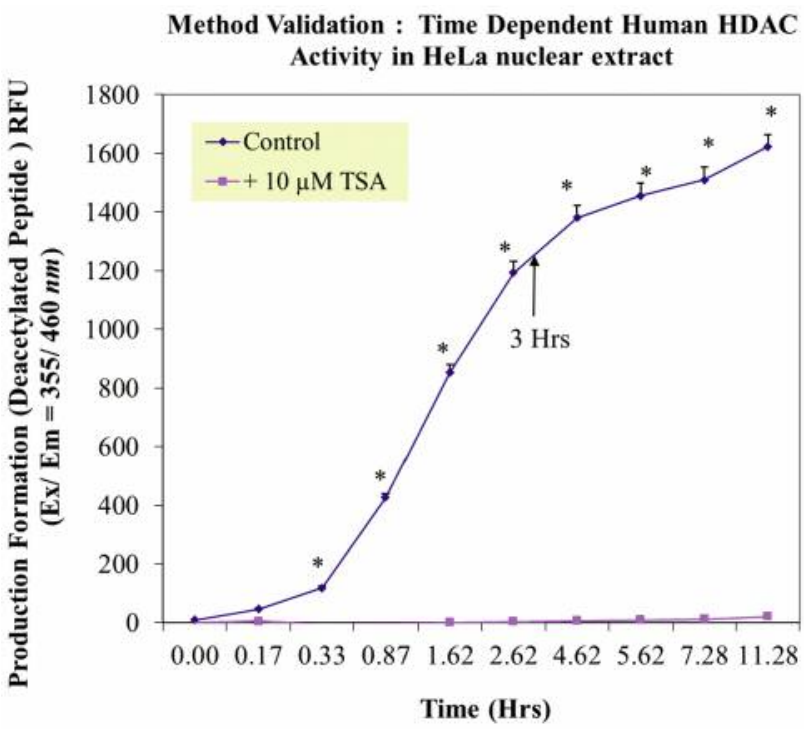

Figure 2. Time-dependent HDAC enzyme activity in crude HeLa nuclear lysate at $37^{\circ} \mathrm{C} \pm 10 \mu \mathrm{M} T S A$ (HDAC inhibitor). The data represent the formation of deacetylated peptide product quantities by relative fluorescent intensity (RFU) 355 (ex) 1460 (em) presented as the mean \pm S.E.M, $n=4$. Time-dependent differences in the control were analyzed by a one-way ANOVA, followed by a Tukey post hoc test. ${ }^{*} p<0.05$. A two-way ANOVA between control and TSA inhibitor established significant differences between the groups $* p<0.01$.

Table I. Biological consequence of HeLa nuclear HDAC enzyme inhibition on the $24 \mathrm{~h}$ cell viability $\left[0.5 \times 10^{5} \mathrm{cells} / \mathrm{ml}\right]$ and 3-4 day cell proliferation $\left[T^{0}=0.04 \times 10^{5} \mathrm{cells} / \mathrm{ml}\right]$ of Hela cells. The data represent HDAC HeLa nuclear enzyme activity $\left(I_{50}\right)$, cell cytotoxicity $\left(L C_{50}\right)$ and cytostatic $\left(I C_{50}\right)$ effects in $\mu \mathrm{g} / \mathrm{mL}$, determined from linear regression of 6 concentrations, $n=4$.

\begin{tabular}{lcccc}
\hline Biological effects - & $\mathrm{IC}_{50}$ & $\mathrm{LC}_{50}$ & $\mathrm{IC}_{50}$ & $\mathrm{Units}$ \\
HeLa cells & $\mathrm{HDAC}$ & Viability & Proliferation & $\mu \mathrm{g} / \mathrm{mL}$ \\
\hline Paclitaxel [No Effect] & $>25^{\mathrm{UL}}$ & $>25^{\mathrm{UL}}$ & 0.005 & $\mu \mathrm{g} / \mathrm{mL}$ \\
Trichostatin A & 0.028 & $>25^{\mathrm{UL}}$ & 0.25 & $\mu \mathrm{g} / \mathrm{mL}$ \\
Apicidin & 0.100 & $>25^{\mathrm{UL}}$ & 0.55 & $\mu \mathrm{g} / \mathrm{mL}$ \\
Superohydoxamic acid & 0.282 & $>25^{\mathrm{UL}}$ & 8.92 & $\mu \mathrm{g} / \mathrm{mL}$ \\
M344 & 0.436 & $>25^{\mathrm{UL}}$ & 1.38 & $\mu \mathrm{g} / \mathrm{mL}$ \\
CL-994 & 0.520 & $>25^{\mathrm{UL}}$ & 2.60 & $\mu \mathrm{g} / \mathrm{mL}$ \\
Valproic Acid & 2.160 & $>25^{\mathrm{UL}}$ & $>25 \mathrm{UL}$ & $\mu \mathrm{g} / \mathrm{mL}$ \\
Sodium phenylbutyrate & 4.710 & $>25^{\mathrm{UL}}$ & $>25 \mathrm{UL}$ & $\mu \mathrm{g} / \mathrm{mL}$ \\
\hline
\end{tabular}

over time, signal of blanks and inhibition by a known HDAC inhibitor (Figure 1). Approximately 2-3 h of incubation at $37^{\circ} \mathrm{C}$ was ample to drive de-acetylated peptide product with sufficient signal/noise ratio for fluorometric detection, being inhibited by a known HDACi (Figure 2), effects which occurred over a dose response presented alongside both negative and positive controls (Figure 3 ). Next a full panel 


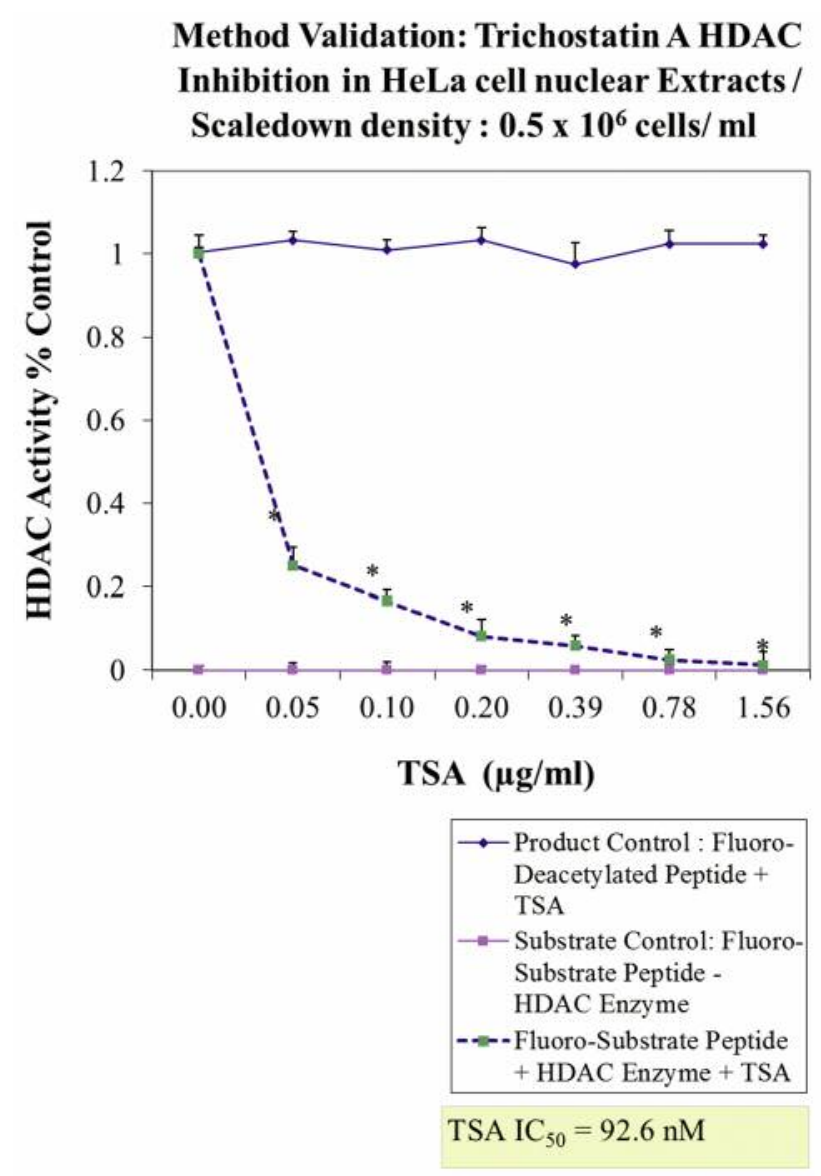

Figure 3. HDAC enzyme activity assay method validation. A 3-h endpoint was sufficient to evaluate HDAC enzyme activity in crude HeLa cell nuclear lysates, which was inhibited by Trichostatin A (TSA) (HDAC inhibitor), with no decay in solvent product control (-Enzyme) and no rise in $R F U$ with substrate (-Enzyme). The data represent HDAC activity (\% control) and are presented as the mean \pm S.E.M, $n=4$ Differences between control and TSA-treated samples were analyzed by a one-way ANOVA, followed by a Tukey post-hoc test. ${ }^{*} p<0.05$.

of HDAC inhibitors were evaluated under uniform conditions and $\mathrm{IC}_{50} \mathrm{~s}$ were established (Table I). Table I also presents biological effects of panel HDAC drugs comparing relative HDACi inhibition in nuclear lysates $\left(\mathrm{IC}_{50} \mathrm{~s}\right)$ with respective $\mathrm{LC}_{50}$ (toxicity) and $\mathrm{IC}_{50}$ (cytostatic-growth inhibition) effects in HeLa Cells. These findings show a predominant anti-mitotic effect rather than cytotoxic effect by known HDAC inhibitors.

Once validated, the HTP screening was conducted on over 1,600 natural products including herbs, seeds, plants, roots, fruits, vegetables, vitamins, organic metabolites, minerals, and drugs for potential HDAC inhibition in nuclear lysates (Figure 4). A 1st tier screening was used to evaluate all compounds at one concentration, to which any compound demonstrating an $\mathrm{IC}_{20}$ less than $600 \mu \mathrm{g} / \mathrm{ml}$ (for crude herbs)

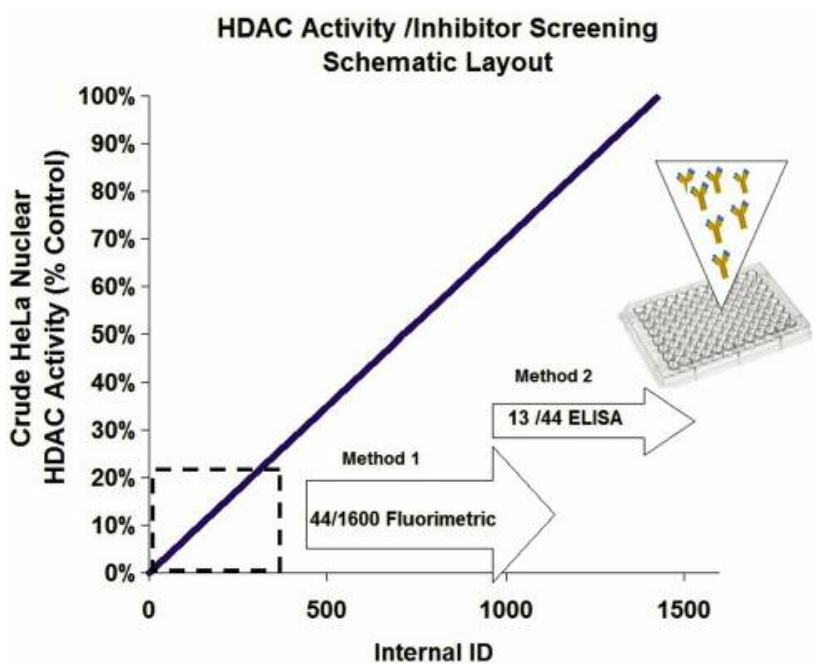

Figure 4. High-throughput schematic. 1,600 natural plant extracts (spices, herbs, teas, vegetables, fruits, seeds, rinds etc. $(<600 \mu \mathrm{g} / \mathrm{mL})$ and polyphenolics $(<240 \mu \mathrm{g} / \mathrm{ml})$ were screened for HDAC activity inhibition in nuclear HeLa cell lysates. Compounds demonstrating an $I C_{20}$ at Tier 1 concentrations using Method 1 (fluorometric) were reevaluated over a minimum of 6 concentrations and $I C_{50}$ s were established. Dual validation was necessary as many natural compounds lead to significant interference with the developer solution in Method 1. Method 2 analysis eliminated the majority as false positives, with only a few natural products confirmed as HDAC inhibitors.

Table II. Summary of Changes: Grapeseed Extract and TSA (HDAC) inhibitor vs. controls using Affymetrix Expression Console Software and Affymetrix ${ }^{\circledR}$ Transcriptome Analysis Console (TAC) Software.

Array Type: miRNA-4_1: Transcriptome of HeLa Cells

\begin{tabular}{lcc}
\hline Total number of genes & 6631 & \\
\hline Differential Expressed: Contol $v s$. GSE & 81 & up-regulated \\
Differential Expressed: Contol $v s$. GSE & 0 & down-regulated \\
Differential Expressed: Contol $v s$. TSA & 35 & up-regulated \\
Differential Expressed: Contol $v s$. TSA & 0 & down-regulated \\
\hline
\end{tabular}

and $240 \mu \mathrm{g} / \mathrm{ml}$ (for all individuals compounds) were reevaluated in a 2 nd screening. Second tier screenings on positive hits were acquired for 10 concentrations (dose response) to establish $\mathrm{IC}_{50} \mathrm{~s}$, with solvent controls run for each compound at varying concentration. Tier 1 and 2 screenings used a common fluorometric activity assay [ab156064] (Abcam Cambridge, MA); Method 1. A major methodological concern was the numerous false positives arising due to inhibition of natural products on the lysine developer reagent (which itself contains an enzyme). Because of numerous interferences associated with Method 
A

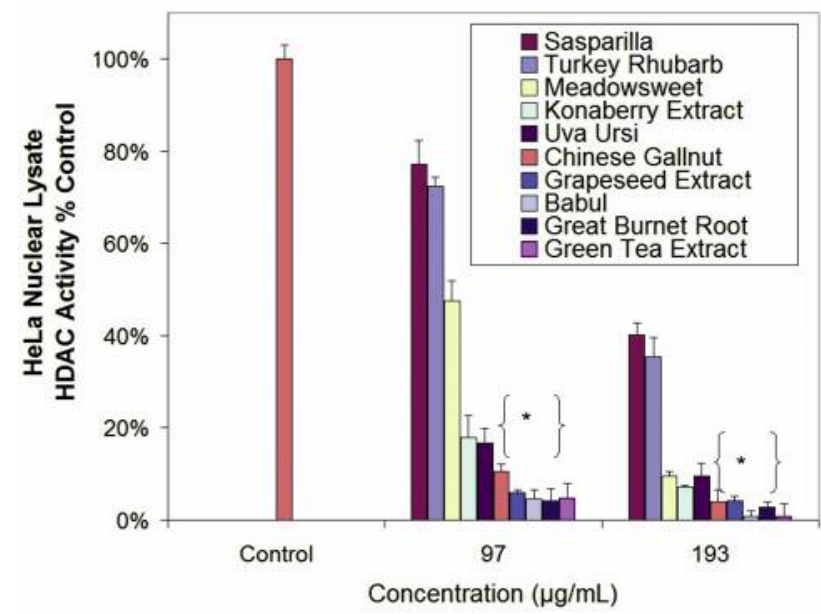

B Natural Plant Derived Constituent HDAC Inhibitors

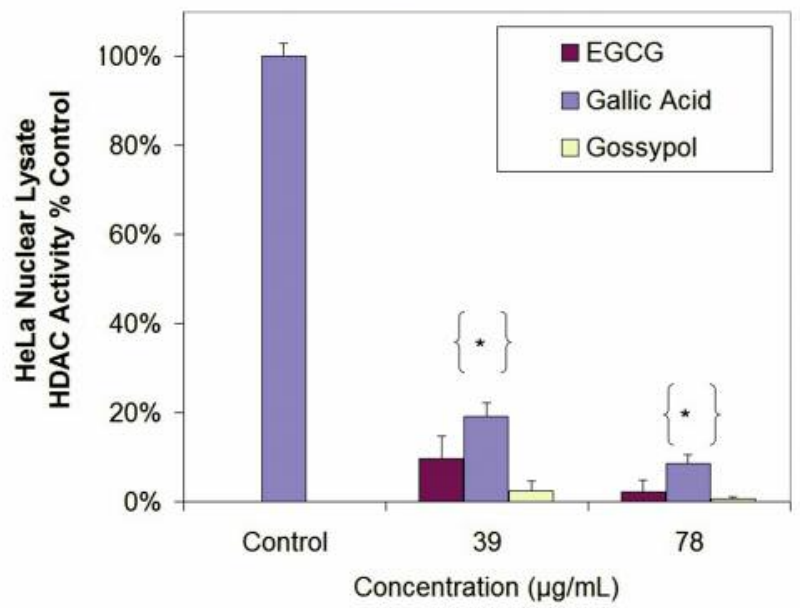

Figure 5. (A,B). Plant based (A) and polyphenolic (B) HDAC inhibitors in HeLa nuclear lysates as determined using the direct specific-activity linked ELISA method. The data represented HDAC Activity as \% controls and presented as the mean $\pm S . E . M, n=3$. Differences between control and treated samples were analyzed by a one-way ANOVA, followed by a Tukey post hoc test. ${ }^{*} p<0.05$.
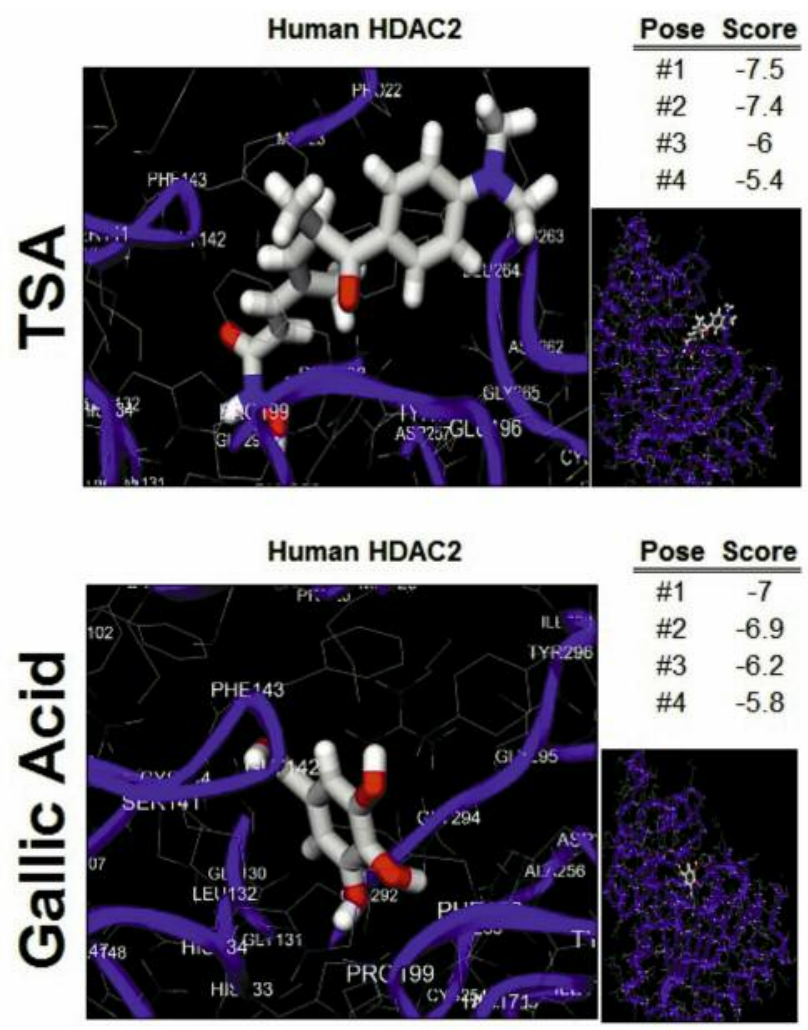
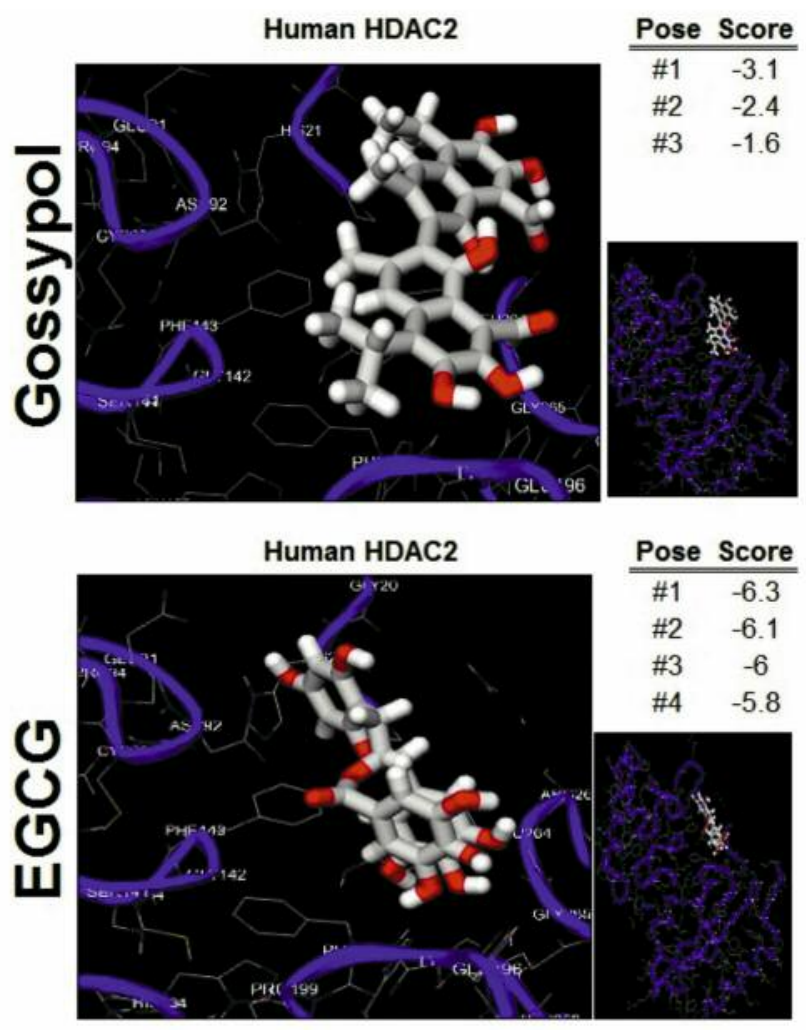
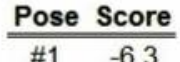

\#2 -6.1

$\# 3-6$

$\# 4 \quad-5.8$

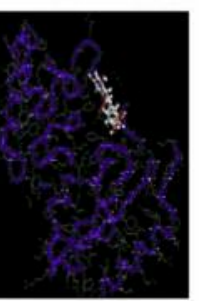

Figure 6. Molecular docking of TSA vs. EGCG, gallic acid and gossypol to human HDAC 2.

1, potential hits were re-validated using Method 2, an ELISA based HDAC activity/ inhibition direct assay \#P-4035. Epigentek Group Inc. (Farmingdale, NY, USA).The data show very few natural products (13) as true HDACis at therapeutic doses (Figure 5A and B). Molecular docking of HDACi polyphenolics: gossypol, EGCG and gallic acid $v s$. TSA, a potent and irreversible inhibitor of human HDAC are presented in Figure 6. 


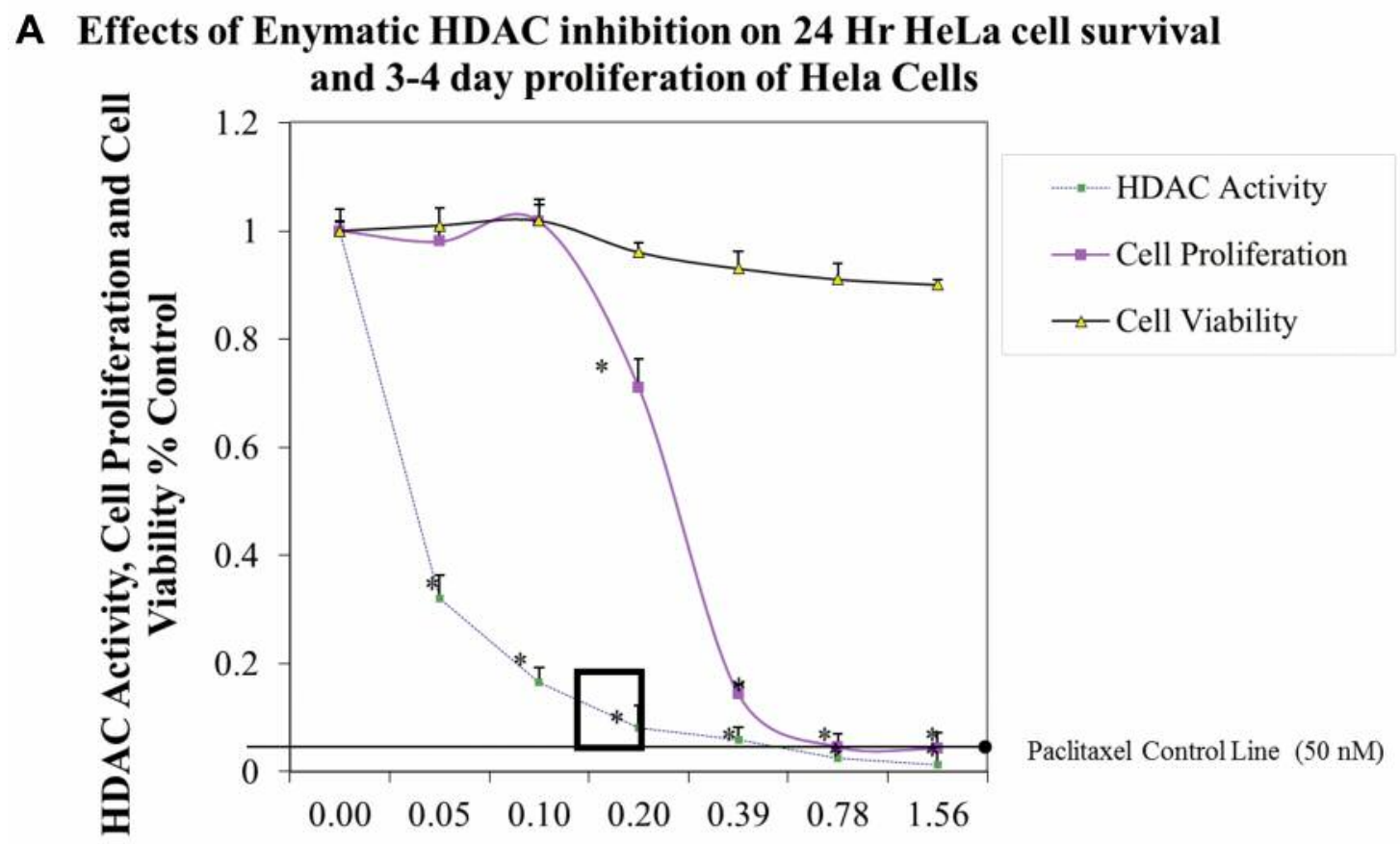

$\operatorname{TSA}(\mu \mathrm{g} / \mathrm{ml})$

\section{B Effects of Enymatic HDAC inhibition on $24 \mathrm{Hr}$ HeLa cell survival and 3-4 day proliferation of Hela Cells}

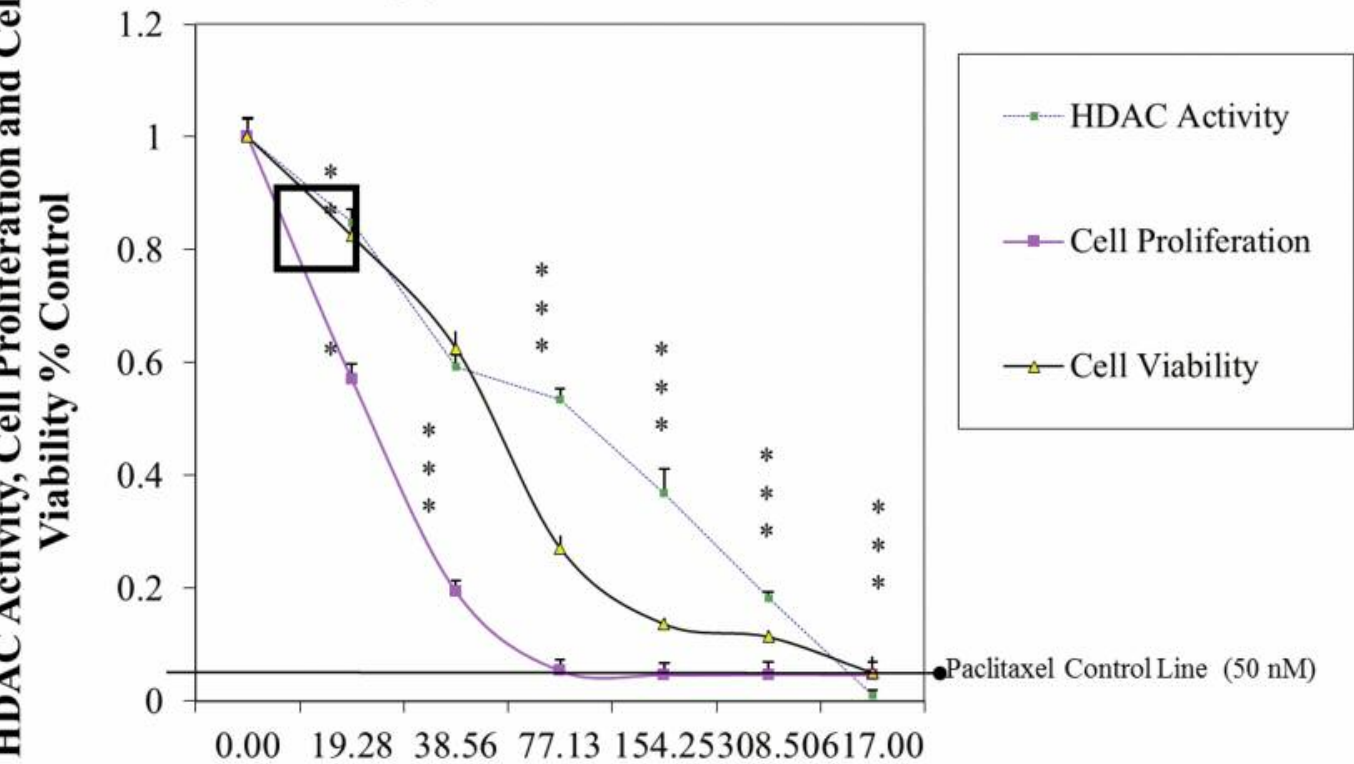

\section{GSE $(\mu \mathrm{g} / \mathrm{ml})$}

Figure 7. A. Correlation between TSA inhibition of Hela cell HDAC enzyme activity and 24 cell viability $\left[0.5 \times 10^{5}\right.$ cells/ml] and 3-4 day cell proliferation $\left[0.04 \times 10^{5} \mathrm{cells} / \mathrm{ml}\right] \mathrm{vs}$. paclitaxel $(50 \mathrm{nM})$ in HeLa cells. The data represent HDAC enzyme activity, cell viability and proliferation as \% controls, and are presented as the mean \pm S.E.M, $n=4$. Differences between control and TSA-treated samples were analyzed by a one-way ANOVA, followed by a Tukey post hoc test. ${ }^{*} p<.05$. B. Evaluation of GSE on $24-h$ cell viability $\left[0.5 \times 10^{5} \mathrm{cells} / \mathrm{ml}\right]$ and $3-4$ day cell proliferation $\left[\mathrm{T0}=0.04 \times 10^{5} \mathrm{cells} / \mathrm{ml}\right]$. The data represent HDAC enzyme activity, cell viability and proliferation as \% controls, and are presented as the mean $\pm S . E . M, n=4$. Differences between control and GSE treated samples were analyzed by a one-way ANOVA, followed by a Tukey post hoc test. *p<0.05. 
Table III. List of elevated miRNA in TSA-treated Hela cells vs. controls: The data include fold change, Transcript ID, Accession Number, and pValue.

\begin{tabular}{|c|c|c|c|c|c|c|c|}
\hline & \multicolumn{3}{|c|}{ Up-regulated miRNA by TSA } & \multicolumn{2}{|c|}{ Bi-weight Avg Signal ( $\log 2)$} & \multirow[b]{2}{*}{ Fold Change } & \multirow[b]{2}{*}{$p$-Value } \\
\hline & Transcript Cluster ID & Accession & Transcript ID & Control & TSA & & \\
\hline 1 & 20517821 & MIMAT0017991 & hsa-miR-3613-3p & 5.28 & 0.98 & 19.79 & 0.01 \\
\hline 2 & 20519463 & MIMAT0019745 & hsa-miR-4668-5p & 4.92 & 1.96 & 7.77 & 0.01 \\
\hline 3 & 20500720 & MIMAT0004587 & hsa-miR-23b-5p & 4.33 & 1.38 & 7.71 & 0.01 \\
\hline 4 & 20500722 & MIMAT0004588 & hsa-miR-27b-5p & 3.25 & 0.67 & 5.98 & 0.04 \\
\hline 5 & 20506712 & MIMAT0005825 & hsa-miR-1180-3p & 2.79 & 0.88 & 3.77 & 0.00 \\
\hline 6 & 20525721 & MIMAT0027660 & hsa-miR-6880-5p & 3.82 & 1.99 & 3.55 & 0.05 \\
\hline 7 & 20525746 & MIMAT0027685 & hsa-miR-6892-3p & 2.66 & 0.87 & 3.46 & 0.03 \\
\hline 8 & 20519672 & MIMAT0019949 & hsa-miR-4785 & 2.53 & 0.94 & 3.01 & 0.04 \\
\hline 9 & 20500120 & MIMAT0004484 & hsa-let-7d-3p & 1.9 & 0.32 & 2.98 & 0.03 \\
\hline 10 & 20500795 & MIMAT0004614 & hsa-miR-193a-5p & 5.6 & 4.16 & 2.72 & 0.03 \\
\hline 11 & 20538197 & U50B & U50B & 1.58 & 0.22 & 2.57 & 0.03 \\
\hline 12 & 20504340 & MIMAT0003268 & hsa-miR-600 & 1.22 & -0.13 & 2.54 & 0.02 \\
\hline 13 & 20535697 & MI0005768 & hsa-mir-943 & 1.12 & -0.19 & 2.48 & 0.05 \\
\hline 14 & 20500139 & MIMAT0000075 & hsa-miR-20a-5p & 7.03 & 5.72 & 2.47 & 0.05 \\
\hline 15 & 20519642 & MIMAT0019919 & hsa-miR-4767 & 1.53 & 0.26 & 2.42 & 0.05 \\
\hline 16 & 20525430 & MIMAT0027369 & hsa-miR-6734-5p & 1.31 & 0.06 & 2.39 & 0.03 \\
\hline 17 & 20535843 & MI0006367 & hsa-mir-1302-6 & 1.15 & -0.09 & 2.36 & 0.05 \\
\hline 18 & 20536916 & MI0017318 & hsa-mir-4686 & 1.91 & 0.69 & 2.32 & 0.04 \\
\hline 19 & 20538310 & ENSG00000252299 & ENSG00000252299 & 2 & 0.8 & 2.3 & 0.04 \\
\hline 20 & 20534343 & MI0000063 & hsa-let-7b & 1.31 & 0.11 & 2.3 & 0.04 \\
\hline 21 & 20506002 & MIMAT0004976 & hsa-miR-933 & 1.98 & 0.79 & 2.28 & 0.04 \\
\hline 22 & 20518793 & MIMAT0018936 & hsa-miR-4423-3p & 1.07 & -0.07 & 2.21 & 0.03 \\
\hline 23 & 20518865 & MIMAT0019006 & hsa-miR-4478 & 1.24 & 0.14 & 2.14 & 0.03 \\
\hline 24 & 20500130 & MIMAT0000070 & hsa-miR-17-5p & 7.77 & 6.69 & 2.12 & 0.02 \\
\hline 25 & 20525457 & MIMAT0027396 & hsa-miR-6748-5p & 3 & 1.93 & 2.11 & 0.02 \\
\hline 26 & 20500115 & MIMAT0000063 & hsa-let-7b-5p & 10.74 & 9.67 & 2.1 & 0.05 \\
\hline 27 & 20500440 & MIMAT0000254 & hsa-miR-10b-5p & 0.9 & -0.16 & 2.08 & 0.04 \\
\hline 28 & 20536854 & MI0017261 & hsa-mir-4634 & 1.6 & 0.55 & 2.07 & 0.03 \\
\hline 29 & 20525631 & MIMAT0027570 & hsa-miR-6835-5p & 1.27 & 0.23 & 2.06 & 0.02 \\
\hline 30 & 20533875 & ENSG00000252112 & ENSG00000252112 & 1.12 & 0.09 & 2.04 & 0.03 \\
\hline 31 & 20537471 & MI0022572 & hsa-mir-6727 & 1.37 & 0.34 & 2.03 & 0.03 \\
\hline 32 & 20536813 & MI0016900 & hsa-mir-4533 & 1.22 & 0.2 & 2.03 & 0.04 \\
\hline 33 & 20533208 & ENSG00000238316 & ENSG00000238316 & 0.78 & -0.23 & 2.02 & 0.01 \\
\hline 34 & 20518937 & MIMAT0019075 & hsa-miR-4535 & 0.99 & -0.03 & 2.02 & 0.03 \\
\hline 35 & 20525446 & MIMAT0027385 & hsa-miR-6742-5p & 0.9 & -0.11 & 2.01 & 0.04 \\
\hline
\end{tabular}

In order to determine if there are any similar influences between an identified plant HDACi and a known HDACi (TSA), we chose grape seed extract (GSE) for further studies. First, the biological effects of GSE and TSA on Hela cells with respective HDAC inhibition (nuclear lysates) are presented in Figure 7A and B. Dual validation of HDAC inhibition by both methods are presented in Figure 8 . To ensure GSE as a true HDACi; we tested numerous supplier batches of GSE from diverse vendors including Bulk Supplements.com/Hard Eight Nutrition LLC (Henderson, NV, USA), Futureceuticals (Momence, IL, USA), and capsules obtained at General Nutrition Center (GNC) and Swanson's (Fargo, ND, USA), all near identical effects.

To evaluate the epigenetic influence of HDACs on whole transcriptome miRNAs, we compared TSA vs. GSE (Bulk supplements (Henderson, NV, USA) at sub-lethal doses (20 $\mu \mathrm{g} / \mathrm{ml} \mathrm{GSE}$ and $0.2 \mu \mathrm{g} / \mathrm{ml}$ TSA) with samples collected at $24 \mathrm{~h}$-for whole genomic evaluation of small non-coding RNA using Affymetrix' miRNA 4.1 Arrays/FlashTag ${ }^{\text {TM }}$ Labeling. The data show that at baseline, there were 6,631 miRNAs expressed in HELA cells, to which 35 were upregulated by TSA and 81 genes up-regulated by GSE (Table II). Changes by TSA on specific miRNAs $v s$. controls in HeLa cells are provided in Table III (fold change) and in Table IV (showing the KEGG pathway association and miRNA target genes). Likewise, changes by GSE on specific miRNAs vs controls in HeLa cells are provided in Table V (fold change) and in Table VI (showing information on KEGG pathway association and miRNA target genes). Corresponding biological target heat maps showing an 
Table IV. Full list of elevated miRNA changes in TSA-treated Hela cells vs controls: The data include miRNAs, KEGG Pathway association, target genes and p-Value.

TSA HDAC inhibitor mediated miRNA up-regulation $v s$. control

\begin{tabular}{|c|c|c|c|c|}
\hline & KEGG pathway & $p$-Value & miRNAS & Target Genes \\
\hline 1 & Pathways in cancer (hsa05200) & $<1 \mathrm{e}-16$ & $\begin{array}{l}\text { hsa-miR-20a-5plTarbase } \\
\text { hsa-miR-17-5plTarbase }\end{array}$ & $\begin{array}{l}\text { E2F1, NRAS, RUNX1, BCL2, MAPK9, CCND1, SMAD4, } \\
\text { HIF1A, MYC, CDKN1A, VEGFA, PTEN, TGFBR2, JAK1 }\end{array}$ \\
\hline 2 & Bladder cancer (hsa05219) & $1.12 \mathrm{E}-10$ & $\begin{array}{l}\text { hsa-miR-20a-5plTarbase } \\
\text { hsa-miR-17-5plTarbase } \\
\text { hsa-let-7b-5plTarbase }\end{array}$ & $\begin{array}{c}\text { E2F1, NRAS, MAP2K2, THBS1, KRAS, CCND1, } \\
\text { MYC, CDKN1A, VEGFA }\end{array}$ \\
\hline 3 & $\begin{array}{l}\text { Chronic myeloid leukemia } \\
\text { (hsa05220) }\end{array}$ & $1.4 \mathrm{E}-08$ & $\begin{array}{l}\text { hsa-miR-20a-5plTarbase } \\
\text { hsa-miR-17-5plTarbase } \\
\text { hsa-let-7b-5plTarbase }\end{array}$ & $\begin{array}{l}\text { E2F1, NRAS, CRKL, MAP2K2, RUNX1, KRAS, CDK6, } \\
\text { CCND1, MYC, SMAD4, CDKN1A, TGFBR2 }\end{array}$ \\
\hline 4 & Hepatitis B (hsa05161) & $2.54 \mathrm{E}-07$ & $\begin{array}{l}\text { hsa-miR-20a-5plTarbase } \\
\text { hsa-miR-17-5plTarbase }\end{array}$ & $\begin{array}{l}\text { E2F1, NRAS, BCL2, MAPK9, CCND1, SMAD4, } \\
\text { MYC, CDKN1A, PTEN. JAK1 }\end{array}$ \\
\hline 5 & Colorectal cancer (hsa05210) & $2.42 \mathrm{E}-06$ & $\begin{array}{l}\text { hsa-miR-20a-5plTarbase } \\
\text { hsa-miR-17-5plTarbase }\end{array}$ & BCL2, MAPK9, CCND1, SMAD4, MYC, TGFBR2 \\
\hline 6 & Melanoma (hsa05218) & 0.000881 & $\begin{array}{c}\text { hsa-miR-20a-5plTarbase } \\
\text { hsa-miR-17-5plTarbase } \\
\text { hsa-let-7b-5plTarbase }\end{array}$ & $\begin{array}{l}\text { E2F1, NRAS, MAP2K2, KRAS, CDK6, CCND1, } \\
\text { CDKN1A, PTEN }\end{array}$ \\
\hline 7 & Pancreatic cancer (hsa05212) & 0.003214 & $\begin{array}{l}\text { hsa-miR-20a-5plTarbase } \\
\text { hsa-miR-17-5plTarbase }\end{array}$ & $\begin{array}{c}\text { E2F1, MAPK9, CCND1, SMAD4, VEGFA, } \\
\text { E2F1, TGFBR2, JAK1 }\end{array}$ \\
\hline 8 & Glioma (hsa05214) & 0.003683 & $\begin{array}{l}\text { hsa-miR-20a-5plTarbase } \\
\text { hsa-miR-17-5plTarbase } \\
\text { hsa-let-7b-5plTarbase }\end{array}$ & $\begin{array}{l}\text { PDGFRA, E2F1, NRAS, MAP2K2, KRAS, CDK6, } \\
\text { CCND1, CDKN1A, PTEN }\end{array}$ \\
\hline 9 & $\begin{array}{l}\text { TGF-beta signaling pathway } \\
\text { (hsa04350) }\end{array}$ & 0.003735 & $\begin{array}{l}\text { hsa-miR-20a-5plTarbase } \\
\text { hsa-miR-17-5plTarbase }\end{array}$ & THBS1, SMAD4, MYC, TGFBR2, BMPR2 \\
\hline 10 & Prostate cancer (hsa05215) & 0.010164 & $\begin{array}{l}\text { hsa-miR-20a-5plTarbase } \\
\text { hsa-miR-17-5plTarbase } \\
\text { hsa-let-7b-5plTarbase }\end{array}$ & $\begin{array}{l}\text { PDGFRA, E2F1, NRAS, MAP2K2, BCL2, } \\
\text { KRAS, CCND1, PDK1, CDKN1A, PTEN }\end{array}$ \\
\hline
\end{tabular}

integration of biological processes associated with changes in miRNAs are shown in Figure 9 for TSA and Figure 10 for GSE. Similar patterned miRNA changes by both GSE and TSA-treated HeLa cells are provided in Table VII. The KEGG pathway for cancer signaling is presented in Figure 11 to which targeted genes for all miRNAs are highlighted in red (TSA) and purple (GSE). These findings demonstrate a rather consistent effect on cancer signaling between a known HDAC drug (TSA) and GSE.

\section{Discussion}

HDAC inhibitors are becoming a well-known class of drugs for cancer treatment, in particular after the FDA approval of Vorinostat and Romidepsin for the treatment of hematologic cancers (2). At least 12 different HDACis are currently in use for clinical trials, and more are being sought to augment chemotherapy $(4,5,7)$, immunotherapy/ cancer vaccines (14) and overcome multi-drug resistance which are common to diverse cytostatic or receptor-mediated drugs $(3,8,9,36-38)$. Further, HDACis can prevent metastasis (24) attenuate epithelial-mesenchymal transition $(11,12)$ influence the

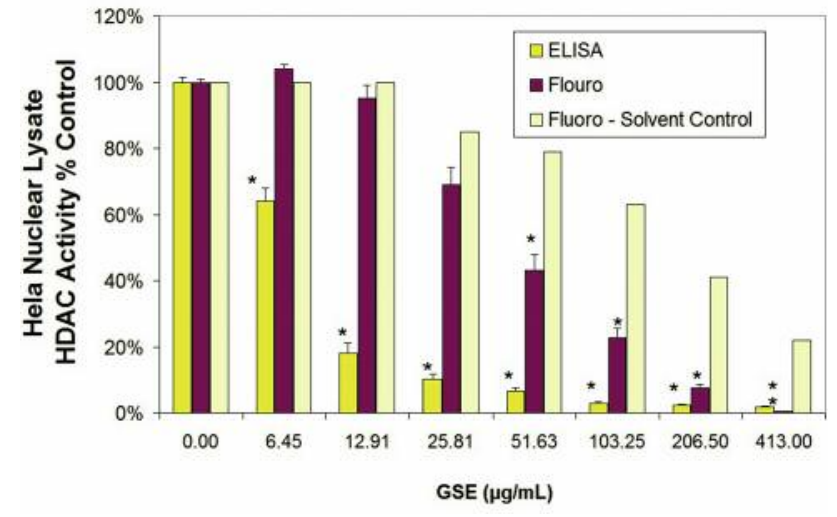

Figure 8. Effects of GSE on HDAC activity comparing a Method 1 (fluorometric) vs. Method 2 (sensitive and specific - ELISA based HDAC Activity/Inhibition Assay). The data represents HDAC Activity as $\%$ controls and are presented as the mean \pm S.E.M, $n=3$. Differences between Control and GSE treated samples were analyzed by a one-way ANOVA, followed by a Tukey post hoc test. ${ }^{*} p<0.05$.

re-expression of tumor suppressors (22) attenuate oncogenes (26) and sustain greater negative impact on targets such as PI3K/AKT/mTOR pathway (28). 
Color Key

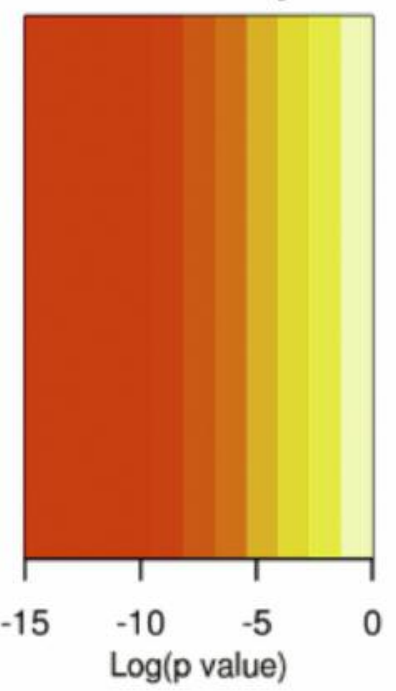

Figure 9. Biological Target (Heatmap) and corresponding Table IV miRNA profile from Pathway Integration of miRNA target genes using DIANA TOOLS - mirPath v.3. TSA vs. Controls in HeLa cells.
hsa-miR-4668-5p/Tarbase hsa-miR-3613-3p/Tarbase hsa-miR-23b-5p/Tarbase hsa-miR-27b-5p/Tarbase hsa-miR-1180/Tarbase hsa-miR-4785/Tarbase hsa-let-7d-3p/Tarbase hsa-miR-600/Tarbase hsa-miR-4767/Tarbase hsa-miR-933/Tarbase hsa-miR-4423-3p/Tarbase hsa-miR-4478/Tarbase hsa-miR-10b-5p/Tarbase hsa-miR-4535/Tarbase hsa-miR-193a-5p/Tarbase hsa-let-7b-5p/Tarbase hsa-miR-17-5p/Tarbase hsa-miR-20a-5p/Tarbase

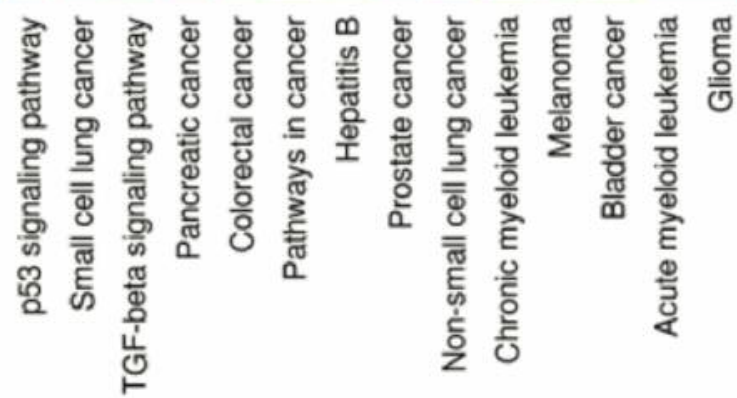




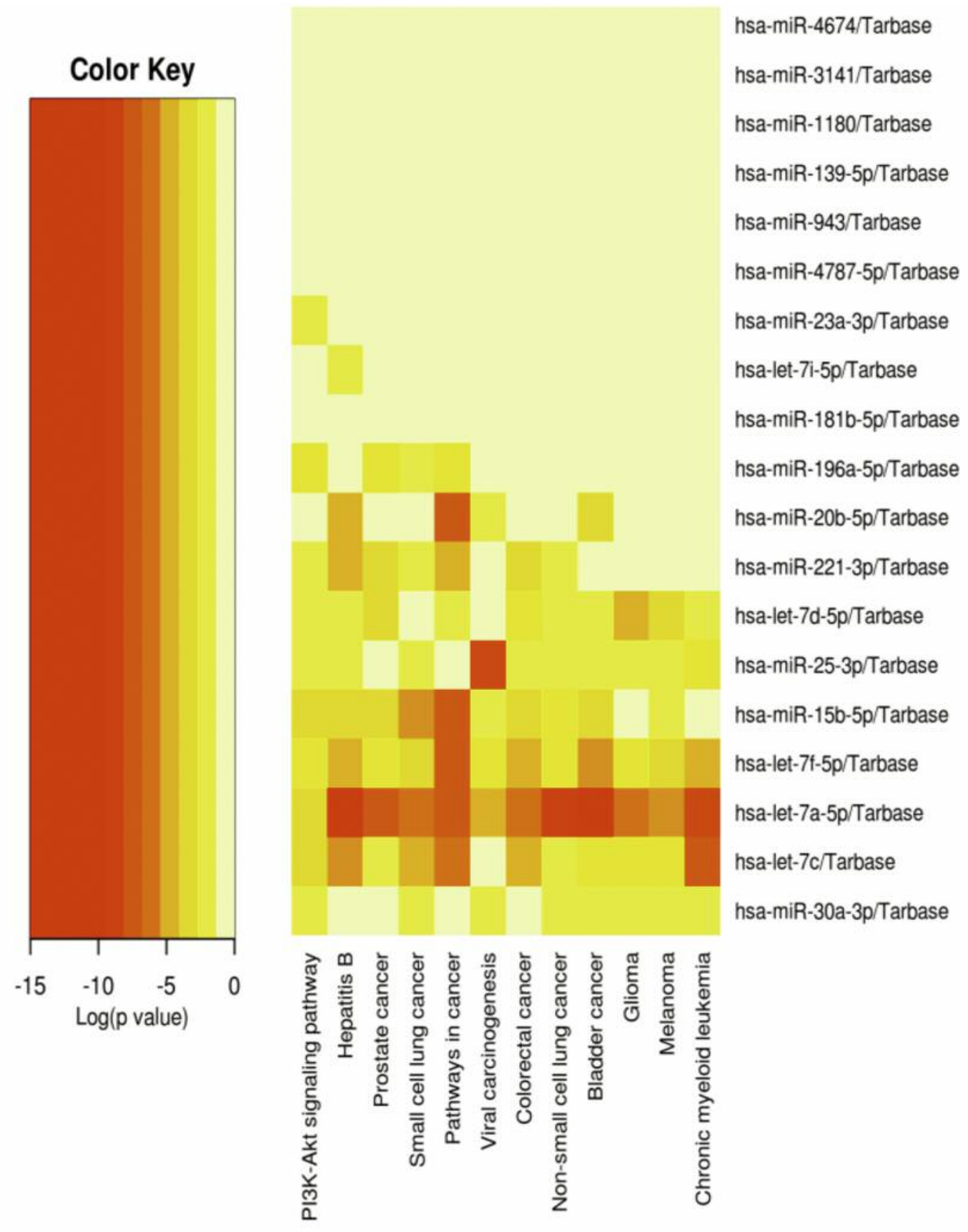

Figure 10. Biological (Heat map) and corresponding Table VI miRNA profile from Pathway Integration of miRNA target genes using DIANA TOOLS - mirPath v.3. GSE vs. Controls in HeLa cells.

HDAC inhibitors were first isolated from microorganisms, and continue to be developed from microbial metabolites (39, 40). Likewise, endogenous microbial fermentation of nondigestible starches in gut microflora can release HDACi butyrate - believed to prevent colon cancer $(31,32)$. Therefore there remains doubt as to if plant based HDACis exist and if so, how they compare with microbial based HDACis.
In this study, we conducted a HTP screening under uniform experimental conditions to identify plant-based or commonly used nutraceuticals with HDAC inhibitory properties. It is imperative to note, unlike many other screenings we have previously conducted, that we faced considerable challenges using common commercially available methodologies to evaluate enzymatic HDAC activity. A major challenge was the 


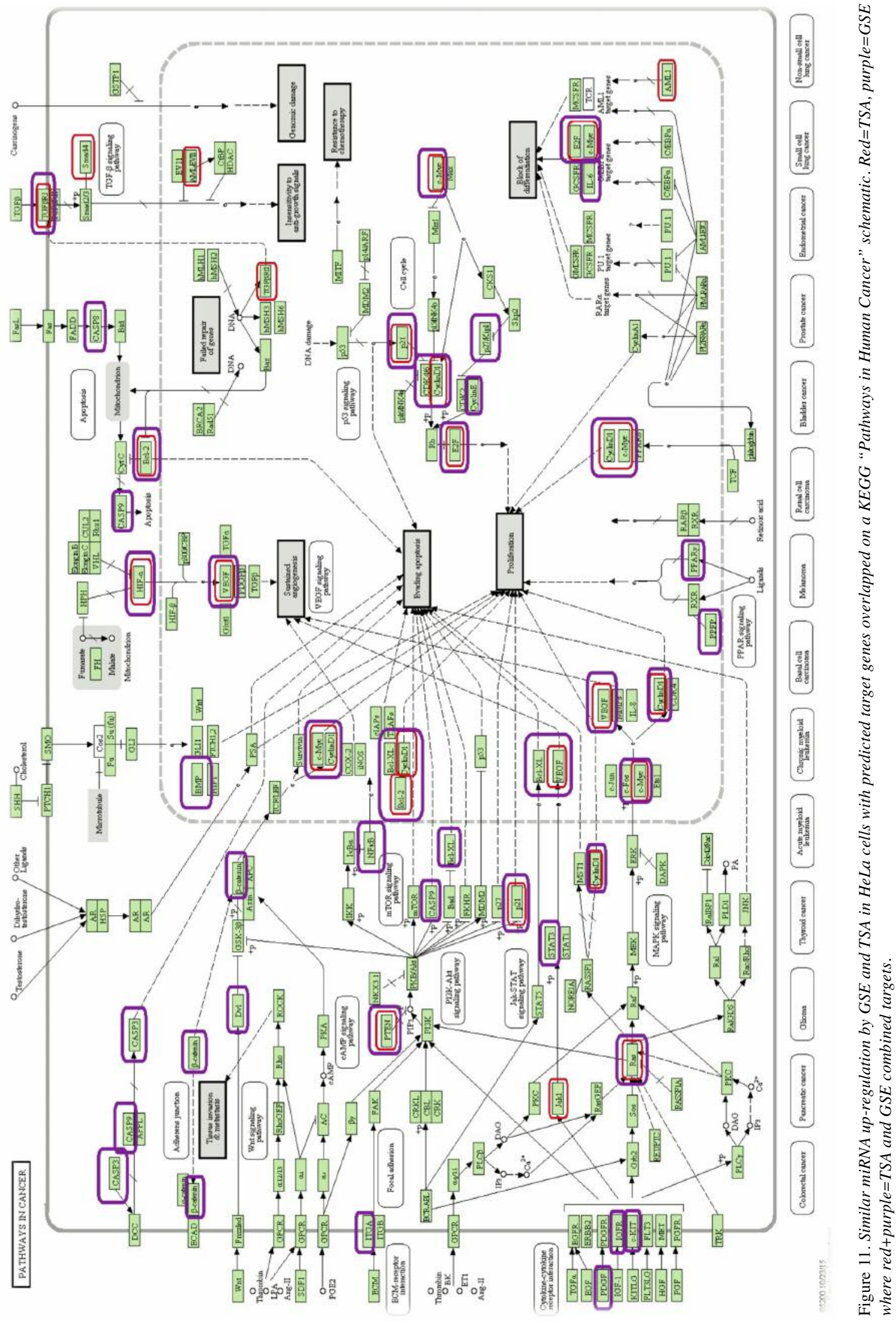


CANCER GENOMICS \& PROTEOMICS 14: 17-34 (2017)

Table V. List of elevated miRNA in GSE-treated Hela cells vs. controls: The data include fold change, Transcript ID, Accession Number, and p-Value.

\begin{tabular}{|c|c|c|c|c|c|c|c|}
\hline & \multicolumn{3}{|c|}{ Up-regulated miRNA by GSE } & \multicolumn{2}{|c|}{ Bi-weight Avg Signal $(\log 2)$} & \multirow[b]{2}{*}{ Fold Change } & \multirow[b]{2}{*}{$p$-value } \\
\hline & Transcript Cluster ID & Accession & Transcript ID & Control & GSE & & \\
\hline 1 & 20525453 & hsa-miR-6746-5p & MIMAT0027392 & 2.86 & -0.12 & 7.87 & 0.00 \\
\hline 2 & 20519576 & hsa-miR-4732-5p & MIMAT0019855 & 3.25 & 0.28 & 7.78 & 0.05 \\
\hline 3 & 20500720 & hsa-miR-23b-5p & MIMAT0004587 & 4.33 & 1.59 & 6.7 & 0.05 \\
\hline 4 & 20506872 & hsa-miR-1275 & MIMAT0005929 & 4.34 & 1.61 & 6.63 & 0.03 \\
\hline 5 & 20518935 & hsa-miR-4534 & MIMAT0019073 & 4.14 & 1.44 & 6.51 & 0.05 \\
\hline 6 & 20525721 & hsa-miR-6880-5p & MIMAT0027660 & 3.82 & 1.14 & 6.43 & 0.02 \\
\hline 7 & 20500722 & hsa-miR-27b-5p & MIMAT0004588 & 3.25 & 0.59 & 6.32 & 0.04 \\
\hline 8 & 20504379 & hsa-miR-629-5p & MIMAT0004810 & 3.58 & 1.03 & 5.86 & 0.04 \\
\hline 9 & 20524053 & hsa-miR-6132 & MIMAT0024616 & 3.88 & 1.47 & 5.31 & 0.04 \\
\hline 10 & 20518432 & hsa-miR-3911 & MIMAT0018185 & 4.99 & 2.68 & 4.94 & 0.05 \\
\hline 11 & 20500393 & hsa-miR-196a-5p & MIMAT0000226 & 4.48 & 2.21 & 4.84 & 0.04 \\
\hline 12 & 20518807 & hsa-miR-4433-3p & MIMAT0018949 & 4.3 & 2.05 & 4.76 & 0.03 \\
\hline 13 & 20525503 & hsa-miR-6771-5p & MIMAT0027442 & 3.9 & 1.73 & 4.52 & 0.03 \\
\hline 14 & 20510799 & hsa-miR-1972 & MIMAT0009447 & 2.93 & 0.8 & 4.37 & 0.05 \\
\hline 15 & 20538194 & $\mathrm{U} 49 \mathrm{~A}$ & U49A & 5.08 & 2.96 & 4.33 & 0.05 \\
\hline 16 & 20500446 & hsa-miR-181b-5p & MIMAT0000257 & 5.24 & 3.19 & 4.16 & 0.01 \\
\hline 17 & 20515627 & hsa-miR-320e & MIMAT0015072 & 4.74 & 2.78 & 3.87 & 0.04 \\
\hline 18 & 20519417 & hsa-miR-4640-5p & MIMAT0019699 & 1.95 & 0.01 & 3.83 & 0.04 \\
\hline 19 & 20500163 & hsa-miR-30a-3p & MIMAT0000088 & 3.94 & 2.01 & 3.83 & 0.05 \\
\hline 20 & 20500394 & hsa-miR-197-5p & MIMAT0022691 & 3.76 & 1.83 & 3.82 & 0.02 \\
\hline 21 & 20535295 & hsa-mir-92b & MI0003560 & 3.83 & 1.92 & 3.76 & 0.02 \\
\hline 22 & 20519441 & hsa-miR-4656 & MIMAT0019723 & 4.28 & 2.37 & 3.76 & 0.04 \\
\hline 23 & 20502237 & hsa-miR-20b-5p & MIMAT0001413 & 4.38 & 2.53 & 3.62 & 0.01 \\
\hline 24 & 20538140 & $\mathrm{U} 17 \mathrm{~b}$ & $\mathrm{U} 17 \mathrm{~b}$ & 6.36 & 4.55 & 3.51 & 0.03 \\
\hline 25 & 20517736 & hsa-miR-4281 & MIMAT0016907 & 5.45 & 3.67 & 3.45 & 0.00 \\
\hline 26 & 20500112 & hsa-let-7a-5p & MIMAT0000062 & 9.15 & 7.38 & 3.4 & 0.01 \\
\hline 27 & 20500120 & hsa-let-7d-3p & MIMAT0004484 & 1.9 & 0.14 & 3.38 & 0.00 \\
\hline 28 & 20500484 & hsa-miR-221-3p & MIMAT0000278 & 6.12 & 4.37 & 3.38 & 0.01 \\
\hline 29 & 20524034 & hsa-miR-6124 & MIMAT0024597 & 2.75 & 1.02 & 3.32 & 0.02 \\
\hline 30 & 20525565 & hsa-miR-6802-5p & MIMAT0027504 & 3.36 & 1.66 & 3.24 & 0.01 \\
\hline 31 & 20536582 & hsa-mir-3679 & MI0016080 & 2.35 & 0.68 & 3.19 & 0.03 \\
\hline 32 & 20537087 & hsa-mir-5095 & MI0018001 & 2.81 & 1.15 & 3.17 & 0.05 \\
\hline 33 & 20519433 & hsa-miR-4651 & MIMAT0019715 & 5.17 & 3.55 & 3.07 & 0.00 \\
\hline 34 & 20500117 & hsa-let-7c-5p & MIMAT0000064 & 8.93 & 7.32 & 3.06 & 0.02 \\
\hline 35 & 20519626 & hsa-miR-4758-5p & MIMAT0019903 & 3.87 & 2.27 & 3.03 & 0.03 \\
\hline 36 & 20534220 & HBII- 135 & HBII-135 & 3.17 & 1.6 & 2.99 & 0.01 \\
\hline 37 & 20500151 & hsa-miR-25-3p & MIMAT0000081 & 4.38 & 2.82 & 2.95 & 0.02 \\
\hline 38 & 20506006 & hsa-miR-937-5p & MIMAT0022938 & 4.34 & 2.8 & 2.91 & 0.02 \\
\hline 39 & 20533073 & ENSG00000212378 & ENSG00000212378 & 6.51 & 4.97 & 2.9 & 0.00 \\
\hline 40 & 20538252 & $\mathrm{U} 78$ & $\mathrm{U} 78$ & 6.51 & 4.97 & 2.9 & 0.00 \\
\hline 41 & 20519488 & hsa-miR-4684-3p & МIMAT0019770 & 1.7 & 0.17 & 2.87 & 0.01 \\
\hline 42 & 20500123 & hsa-let-7f-5p & MIMAT0000067 & 6.2 & 4.69 & 2.85 & 0.03 \\
\hline 43 & 20538192 & U49A & $\mathrm{U} 49 \mathrm{~A}$ & 3.56 & 2.1 & 2.76 & 0.05 \\
\hline 44 & 20538195 & U49B & U49B & 3.56 & 2.1 & 2.76 & 0.05 \\
\hline 45 & 20538247 & U75 & U75 & 3.93 & 2.48 & 2.73 & 0.01 \\
\hline 46 & 20526178 & hsa-miR-7110-5p & MIMAT0028117 & 3.77 & 2.33 & 2.7 & 0.02 \\
\hline 47 & 20525587 & hsa-miR-6813-5p & MIMAT0027526 & 4.13 & 2.69 & 2.7 & 0.02 \\
\hline 48 & 20504341 & hsa-miR-601 & МIMAT0003269 & 1.86 & 0.44 & 2.68 & 0.01 \\
\hline 49 & 20519636 & hsa-miR-4763-3p & MIMAT0019913 & 5.63 & 4.25 & 2.61 & 0.04 \\
\hline 50 & 20538244 & $\mathrm{U} 73 \mathrm{a}$ & U73a & 4.67 & 3.3 & 2.59 & 0.03 \\
\hline 51 & 20501286 & hsa-miR-151a-5p & MIMAT0004697 & 6.55 & 5.18 & 2.59 & 0.04 \\
\hline 52 & 20538253 & $\mathrm{U} 78$ & $\mathrm{U} 78$ & 6.19 & 4.83 & 2.57 & 0.01 \\
\hline 53 & 20538193 & U49A & $\mathrm{U} 49 \mathrm{~A}$ & 4.84 & 3.5 & 2.53 & 0.05 \\
\hline 54 & 20519474 & hsa-miR-4674 & MIMAT0019756 & 4.67 & 3.35 & 2.5 & 0.04 \\
\hline 55 & 20538254 & U79 & U79 & 3.48 & 2.16 & 2.49 & 0.05 \\
\hline 56 & 20538248 & U75 & U75 & 3.89 & 2.59 & 2.46 & 0.02 \\
\hline
\end{tabular}




\begin{tabular}{|c|c|c|c|c|c|c|c|}
\hline & \multicolumn{3}{|c|}{ Up-regulated miRNA by GSE } & \multicolumn{2}{|c|}{ Bi-weight Avg Signal $(\log 2)$} & \multirow[b]{2}{*}{ Fold Change } & \multirow[b]{2}{*}{$p$-value } \\
\hline & Transcript Cluster ID & Accession & Transcript ID & Control & GSE & & \\
\hline 57 & 20515550 & hsa-miR-3141 & MIMAT0015010 & 6.49 & 5.2 & 2.46 & 0.03 \\
\hline 58 & 20525559 & hsa-miR-6799-5p & MIMAT0027498 & 1.7 & 0.42 & 2.43 & 0.00 \\
\hline 59 & 20538199 & U50 & U50 & 5.06 & 3.78 & 2.42 & 0.01 \\
\hline 60 & 20538159 & $\mathrm{U} 30$ & $\mathrm{U} 30$ & 5.17 & 3.9 & 2.41 & 0.01 \\
\hline 61 & 20500146 & hsa-miR-23a-3p & MIMAT0000078 & 9.66 & 8.39 & 2.4 & 0.03 \\
\hline 62 & 20506712 & hsa-miR-1180-3p & MIMAT0005825 & 2.79 & 1.55 & 2.37 & 0.04 \\
\hline 63 & 20525491 & hsa-miR-6765-5p & MIMAT0027430 & 5.8 & 4.56 & 2.36 & 0.02 \\
\hline 64 & 20538300 & $\operatorname{mgh} 28 \mathrm{~S}-2411$ & $\operatorname{mgh} 28 \mathrm{~S}-2411$ & 4.8 & 3.56 & 2.36 & 0.03 \\
\hline 65 & 20538249 & U76 & U76 & 7.8 & 6.58 & 2.33 & 0.04 \\
\hline 66 & 20523000 & hsa-miR-6068 & MIMAT0023693 & 2.72 & 1.53 & 2.28 & 0.01 \\
\hline 67 & 20500432 & hsa-miR-139-5p & MIMAT0000250 & 0.99 & -0.18 & 2.25 & 0.03 \\
\hline 68 & 20535697 & hsa-mir-943 & MI0005768 & 1.12 & -0.04 & 2.24 & 0.04 \\
\hline 69 & 20500718 & hsa-miR-15b-5p & MIMAT0000417 & 6.06 & 4.9 & 2.24 & 0.04 \\
\hline 70 & 20537261 & hsa-mir-6089-1 & MI0020366 & 3.85 & 2.71 & 2.2 & 0.02 \\
\hline 71 & 20537862 & hsa-mir-6089-2 & MI0023563 & 3.85 & 2.71 & 2.2 & 0.02 \\
\hline 72 & 20519679 & hsa-miR-4787-5p & MIMAT0019956 & 9.25 & 8.15 & 2.16 & 0.05 \\
\hline 73 & 20525416 & hsa-miR-6727-5p & MIMAT0027355 & 7.88 & 6.77 & 2.16 & 0.05 \\
\hline 74 & 20538197 & U50B & U50B & 1.58 & 0.49 & 2.13 & 0.03 \\
\hline 75 & 20500715 & hsa-let-7i-5p & MIMAT0000415 & 6.67 & 5.58 & 2.12 & 0.00 \\
\hline 76 & 20538255 & U80 & U80 & 1.88 & 0.82 & 2.09 & 0.04 \\
\hline 77 & 20500119 & hsa-let-7d-5p & MIMAT0000065 & 8.26 & 7.2 & 2.09 & 0.04 \\
\hline 78 & 20523021 & hsa-miR-6089 & MIMAT0023714 & 8.93 & 7.89 & 2.06 & 0.04 \\
\hline 79 & 20532675 & ACA44 & ACA 44 & 5.34 & 4.32 & 2.03 & 0.01 \\
\hline 80 & 20534056 & ENSG00000252840 & ENSG00000252840 & 5.34 & 4.32 & 2.03 & 0.01 \\
\hline 81 & 20529779 & hsa-miR-8069 & MIMAT0030996 & 8.37 & 7.36 & 2.02 & 0.03 \\
\hline
\end{tabular}

numerous false-positives which originated from the inhibition of natural products on fluorimetric lysine developer reagents (which themselves contain an enzyme). The inability to ascertain HDACi due to solvent decay required validation using a more robust and sensitive activity-based method. With dual detection methods, we were able to ascertain only 13 plant-based HDACi which included grapeseed extract (GSE), great burnet root (Sanguisorba Officinalis), Babul (Acacia arabica), Chinese gallnut (Melaphis Chinensis), konaberry extract (Coffea arabica), Uva Ursi (Arctostaphylos uva ursi), epigallocatechin gallate (EGCG), green tea (Camellia sinensis), meadowsweet (Filipendula ulmaria), sassafras (Sassafras Officinale), Turkey Rhubarb (Rheum palmatum), gossypol and gallic acid.

Grapeseed extract. GSE has an extensive history in chemoprevention, yet there are very few studies demonstrating its influence on the epigenome. In vivo studies have demonstrated the capacity of dietary intake of GSE proanthocyanidins $(0.2 \%$ and $0.5 \%, \mathrm{w} / \mathrm{w})$ to attenuate DNA damage by UV radiation-induced as well as attenuate advanced melanoma, malignant transformation of papilloma to carcinoma (41-43) and other diverse tumors (e.g., hormone-refractory human prostate carcinoma) (44). These effects have also been observed in humans, elucidated by epidemiological studies such as the Vitamins And Lifestyle (VITAL) cohort study. In the VITAL study, dietary intake of GSE is inversely related to the risk of hematologic malignancies, possibly indicating a connection to its capacity to inhibit HDAC (45). Intake of GSE is also a correlate to reduced cutaneous squamous cell carcinoma and prostate cancer, while many other dietary supplements fail to show a correlation (46). While few reports exist on GSE and epigenetic targets, of those that do, they show influences on tumor suppressor microRNAs (47) global DNA methylation, DNA methyltransferase (DNMT) activity and expression, and changes in altered acetylated lysines $\mathrm{H} 3$ marks (48) in a similar demonstration to the results of this study.

The findings of the current study not only confirm major changes in microRNAs initiated by GSE similar to the known HDACi TSA, but also show that TSA and GSE lead to 6 overlapping cancer patterns on miRNAs with remarkable similarity in fold change - GSE/TSA fold upregulation (hsa-let-7d-3p, 3.38/2.98, hsa-miR-23b-5p: 6.7/ 
Table VI. Full list of elevated miRNA changes in GSE-treated Hela cells vs controls: The data include miRNAs, KEGG Pathway association, target genes and $p$-Value.

GSE HDAC inhibitor mediated miRNA up-regulation $v s$. control

\begin{tabular}{|c|c|c|c|c|}
\hline & KEGG pathway & $p$-Value & miRNAS & Target Genes \\
\hline 1 & Pathways in cancer (hsa05200) & $6.59 \mathrm{E}-14$ & $\begin{array}{l}\text { hsa-miR-196a-5plTarbase } \\
\text { hsa-miR-20b-5plTarbase } \\
\text { hsa-let-7a-5plTarbase } \\
\text { hsa-miR-221-3plTarbase } \\
\text { hsa-let-7clTarbase } \\
\text { hsa-let-7f-5plTarbase } \\
\text { hsa-miR-15b-5plTarbase } \\
\text { hsa-let-7d-5plTarbase }\end{array}$ & $\begin{array}{l}\text { FOS, STAT3, E2F1, TGFBR1, NFKB1, NRAS, BCL2, } \\
\text { CDKN1B, IGF1R, KRAS, CDK6, ITGAV, CASP3, CCND1, } \\
\text { CTNNB1, HIF1A, E2F3, MYC, KIT, CASP9, HRAS, } \\
\text { PPARG, CASP8, BCL2L1, CCNE1, CDKN1A, } \\
\text { VEGFA, PTEN, IL6, DVL2, BMP4, PDGFA, }\end{array}$ \\
\hline 2 & Hepatitis B (hsa05161) & $2.84 \mathrm{E}-13$ & $\begin{array}{c}\text { hsa-miR-20b-5plTarbase } \\
\text { hsa-let-7a-5plTarbase } \\
\text { hsa-miR-221-3plTarbase } \\
\text { hsa-let-7clTarbase } \\
\text { hsa-miR-25-3plTarbase } \\
\text { hsa-let-7f-5plTarbase } \\
\text { hsa-miR-15b-5plTarbase } \\
\text { hsa-let-7i-5plTarbase } \\
\text { hsa-let-7d-5plTarbase }\end{array}$ & $\begin{array}{l}\text { FOS, STAT3, E2F1, TGFBR1, NFKB1, E2F2, NRAS, } \\
\text { BCL2, CDKN1B, TLR4, KRAS, CDK6, TICAM1, TP53, } \\
\text { EGR3, CASP3, CCND1, E2F3, MYC, TBK1, CASP9, } \\
\text { HRAS, CASP8, CCNE1, CDKN1A, PTEN, IL6 }\end{array}$ \\
\hline 3 & Bladder cancer (hsa05219) & $3.24 \mathrm{E}-05$ & $\begin{array}{l}\text { hsa-miR-30a-3plTarbase } \\
\text { hsa-miR-20b-5plTarbase } \\
\text { hsa-let-7a-5plTarbase } \\
\text { hsa-let-7clTarbase } \\
\text { hsa-miR-25-3plTarbase } \\
\text { hsa-let-7f-5plTarbase } \\
\text { hsa-miR-15b-5plTarbase } \\
\text { hsa-let-7d-5plTarbase }\end{array}$ & $\begin{array}{l}\text { E2F1, E2F2, NRAS, THBS1, KRAS, TP53, } \\
\text { CCND1, MYC, HRAS, CDKN1A, VEGFA }\end{array}$ \\
\hline 4 & $\begin{array}{l}\text { Chronic myeloid leukemia } \\
\text { (hsa05220) }\end{array}$ & $9.82 \mathrm{E}-05$ & $\begin{array}{l}\text { hsa-miR-30a-3plTarbase } \\
\text { hsa-let-7a-5plTarbase } \\
\text { hsa-let-7clTarbase } \\
\text { hsa-miR-25-3plTarbase } \\
\text { hsa-let-7f-5plTarbase } \\
\text { hsa-let-7d-5plTarbase }\end{array}$ & $\begin{array}{l}\text { E2F1, TGFBR1, NFKB1, E2F2, NRAS, KRAS, CDK6, } \\
\text { TP53, CCND1, MYC, HRAS, BCL2L1, CDKN1A }\end{array}$ \\
\hline 5 & $\begin{array}{l}\text { Small cell lung cancer } \\
\text { (hsa05222) }\end{array}$ & 0.000839 & $\begin{array}{l}\text { hsa-miR-196a-5plTarbase } \\
\text { hsa-miR-30a-3plTarbase } \\
\text { hsa-let-7a-5plTarbase } \\
\text { hsa-miR-221-3plTarbase } \\
\text { hsa-let-7clTarbase } \\
\text { hsa-miR-25-3plTarbase } \\
\text { hsa-let-7f-5plTarbase } \\
\text { hsa-miR-15b-5plTarbase }\end{array}$ & $\begin{array}{l}\text { E2F1, NFKB1, E2F2 ,BCL2, CDKN1B, CDK6, } \\
\text { TP53, ITGAV, CCND1, E2F3, MYC, } \\
\text { CASP9, BCL2L1, CCNE1, PTEN }\end{array}$ \\
\hline 6 & Prostate cancer (hsa05215) & 0.00102 & $\begin{array}{l}\text { hsa-miR-196a-5plTarbase } \\
\text { hsa-let-7a-5plTarbase } \\
\text { hsa-miR-221-3p|Tarbase } \\
\text { hsa-let-7clTarbase } \\
\text { hsa-let-7f-5plTarbase } \\
\text { hsa-miR-15b-5plTarbase } \\
\text { hsa-let-7d-5plTarbase }\end{array}$ & $\begin{array}{c}\text { E2F1, NFKB1, E2F2, NRAS, BCL2, CDKN1B, IGF1R, } \\
\text { KRAS, CCND1, CTNNB1, E2F3, CASP9, HRAS, } \\
\text { CCNE1, CDKN1A, PTEN, PDGFA }\end{array}$ \\
\hline 7 & Colorectal cancer (hsa05210) & 0.003297 & $\begin{array}{l}\text { hsa-let-7a-5plTarbase } \\
\text { hsa-miR-221-3plTarbase } \\
\text { hsa-let-7clTarbase } \\
\text { hsa-miR-25-3plTarbase } \\
\text { hsa-let-7f-5plTarbase } \\
\text { hsa-miR-15b-5plTarbase } \\
\text { hsa-let-7d-5plTarbase }\end{array}$ & $\begin{array}{l}\text { FOS, TGFBR1, BCL2, KRAS, TP53, CASP3, } \\
\text { CCND1, CTNNB1, MYC, CASP9 }\end{array}$ \\
\hline 8 & $\begin{array}{l}\text { PI3K-Akt signaling pathway } \\
\text { (hsa04151) }\end{array}$ & 0.004919 & $\begin{array}{l}\text { hsa-miR-196a-5plTarbase } \\
\text { hsa-miR-30a-3plTarbase }\end{array}$ & $\begin{array}{l}\text { NFKB1, NRAS, THBS1, CCND2, BCL2, CDKN1B, } \\
\text { IGF1R, KRAS, CDK6, TP53, ITGAV, DDIT4, CCND1, }\end{array}$ \\
\hline
\end{tabular}


Table VI. Continued

GSE HDAC inhibitor mediated miRNA up-regulation $v s$. control

\begin{tabular}{|c|c|c|c|c|}
\hline & KEGG pathway & $p$-Value & miRNAS & Target Genes \\
\hline & & & $\begin{array}{l}\text { hsa-let-7a-5plTarbase } \\
\text { hsa-miR-221-3plTarbase } \\
\text { hsa-let-7clTarbase } \\
\text { hsa-miR-25-3plTarbase } \\
\text { hsa-let-7f-5plTarbase } \\
\text { hsa-miR-23a-3plTarbase } \\
\text { hsa-miR-15b-5plTarbase } \\
\text { hsa-let-7d-5plTarbase }\end{array}$ & $\begin{array}{l}\text { MYC, KIT, CASP9, HRAS, BCL2L1, CCNE1, FOXO3, } \\
\text { CDKN1A, VEGFA, PTEN, IL6, BCL2L11, IL6R, PDGFA }\end{array}$ \\
\hline 9 & Glioma (hsa05214) & 0.020994 & $\begin{array}{c}\text { hsa-miR-30a-3plTarbase } \\
\text { hsa-let-7a-5plTarbase } \\
\text { hsa-let-7clTarbase } \\
\text { hsa-miR-25-3plTarbase } \\
\text { hsa-let-7f-5plTarbase } \\
\text { hsa-let-7d-5plTarbase }\end{array}$ & $\begin{array}{l}\text { E2F1, E2F2, NRAS, IGF1R, KRAS, CDK6, } \\
\text { TP53, CCND1, HRAS, CDKN1A, PDGFA }\end{array}$ \\
\hline 10 & $\begin{array}{l}\text { Viral carcinogenesis } \\
\quad(\text { hsa05203) }\end{array}$ & 0.026785 & $\begin{array}{l}\text { hsa-miR-30a-3plTarbase } \\
\text { hsa-miR-20b-5plTarbase } \\
\text { hsa-let-7a-5plTarbase } \\
\text { hsa-miR-25-3plTarbase } \\
\text { hsa-let-7f-5plTarbase } \\
\text { hsa-miR-15b-5plTarbase }\end{array}$ & $\begin{array}{l}\text { STAT3, NFKB1, NRAS, CCND2, KRAS, } \\
\text { CDK6, TP53, EGR3, CASP3, CCND1, } \\
\text { HRAS, KAT2B, CASP8, CCNE1, CDKN1A }\end{array}$ \\
\hline
\end{tabular}

7.71, hsa-miR-27b-5p 6.32/5.98, hsa-miR-1180-3p 2.37/3.77, hsa-miR-6880-5p 6.43/3.55 and hsa-mir-943 2.24/2.48). For TSA, up-regulation of hsa-miR-27b-5p, hsa-miR-23b-5p, hsa-miR-3613-3p, hsa-miR-20a-5p and hsa-miR-17-5p are target-specific for destruction of oncogenes including E2F1, NRAS, BCL2, MAPK9, HIF1a, SMAD 4 , MYC, CDKN1a, VEGFA, JAK1, TGFBR2. In the case of GSE, greater than 4-fold elevation alone for miRNAs such as hsa-miR-23b-5p, hsa-miR-196a-5p, hsa-miR-629-5p, hsa-miR-1275 hsa-miR$27 \mathrm{~b}-5 \mathrm{p}$ are predicted to down-regulate over 80 cancer pathway genes, including the aforementioned as well as STAT3, FOS, TGFBR1, NFKB1, E2F2,3, CDKN1B, BRAF, IGF1R, JUN, BIRC3 KRAS, CDK4 and 6, HRAS or invasive oncogenes such as ITGAV.

In summary, the data from this study show several natural product HDACis, and a consequential pattern associated with elevated tumor-suppressor miRNAs. While there is a wealth of information in this report, future studies will be required to determine what compounds within GSE are responsible for these effects, possibly being gallic acid. Furthermore, future studies will be required to evalute if HDACis across the board lead to patterned up-regulation of tumor-suppressing miRNAs and epigenetic influences by great burnet root (Sanguisorba Officinalis), Babul (Acacia arabica), Chinese gallnut (Melaphis Chinensis), konaberry extract (Coffea arabica) and Uva Ursi (Arctostaphylos uva ursi).
Table VII. Similar patterned miRNA changes in GSE and TSA-treated HeLa cells.

OVERLAPPING miRNA up-regulation by TSA and GSE

\begin{tabular}{lcccc}
\hline & \multicolumn{2}{c}{$\begin{array}{c}\text { Fold up-regulation } \\
\text { vs. Control }\end{array}$} & \multicolumn{2}{c}{$\begin{array}{c}\text { Fold up-regulation } \\
\text { vs. Control }\end{array}$} \\
\cline { 2 - 5 } Transcript ID & GSE & $p$-Value & TSA & $p$-Value \\
\hline hsa-let-7d-3p & 3.38 & 0.005 & 2.98 & 0.027 \\
hsa-miR-23b-5p & 6.70 & 0.049 & 7.71 & 0.009 \\
hsa-miR-27b-5p & 6.32 & 0.038 & 5.98 & 0.042 \\
hsa-miR-1180-3p & 2.37 & 0.045 & 3.77 & 0.004 \\
hsa-miR-6880-5p & 6.43 & 0.016 & 3.55 & 0.046 \\
hsa-mir-943 & 2.24 & 0.035 & 2.48 & 0.048 \\
\hline
\end{tabular}

\section{Conflicts of Interest}

The Authors wish to confirm that there are no known conflicts of interest associated with this publication and there has been no significant financial support for this work that could have influenced its outcome.

\section{Acknowledgements}

This research was supported by the National Institute of Minority Health and Health Disparities of the National Institutes of Health through Grant Number 8 G12MD007582-28 and Grant Number 
1P20 MD006738-01. We are grateful for the assistance of Jacob Crowley from Affymetrix Corporation (Santa Clara, CA, USA), and all the graduate students who assisted with sample prep and maintenance of the natural product library.

\section{References}

1 Mazzio EA and Soliman KF: Basic concepts of epigenetics: Impact of environmental signals on gene expression. Epigenetics 7(2): 119-130, 2012.

2 Yoon S and Eom GH: Hdac and hdac inhibitor: From cancer to cardiovascular diseases. Chonnam Med J 52(1): 1-11, 2016.

3 Xue K, Gu JJ, Zhang Q, Mavis C, Hernandez-Ilizaliturri FJ, Czuczman MS and Guo Y: Vorinostat, a histone deacetylase (hdac) inhibitor, promotes cell cycle arrest and re-sensitizes rituximab- and chemo-resistant lymphoma cells to chemotherapy agents. J Cancer Res Clin Oncol 142(2): 379-387, 2016.

4 Zhijun H, Shusheng W, Han M, Jianping L, Li-Sen Q and Dechun L: Pre-clinical characterization of 4sc-202, a novel class i hdac inhibitor, against colorectal cancer cells. Tumour Biol, 2016.

5 Zhang X, Jiang SJ, Shang B and Jiang HJ: Effects of histone deacetylase inhibitor trichostatin a combined with cisplatin on apoptosis of a549 cell line. Thorac Cancer 6(2): 202-208, 2015.

6 Jiang Y, Li X, Hou J, Ding Y, Zhang J, Xu W and Zhang Y: Discovery of multi-target anticancer agents based on hdac inhibitor ms-275 and 5-fu. Med Chem 12(1): 30-36, 2016.

7 Kumar B, Yadav A, Lang JC, Teknos TN and Kumar P: Suberoylanilide hydroxamic acid (saha) reverses chemoresistance in head and neck cancer cells by targeting cancer stem cells via the down-regulation of nanog. Genes Cancer 6(3-4): 169-181, 2015.

8 Wu CP, Hsieh YJ, Hsiao SH, Su CY, Li YQ, Huang YH, Huang $\mathrm{CW}$, Hsieh $\mathrm{CH}$, Yu JS and Wu YS: Human atp-binding cassette transporter abcg2 confers resistance to cudc-907, a dual inhibitor of histone deacetylase and phosphatidylinositol 3-kinase. Mol Pharm 13(3): 784-794, 2016.

9 Kaewpiboon C, Srisuttee R, Malilas W, Moon J, Oh S, Jeong HG, Johnston RN, Assavalapsakul W and Chung YH: Upregulation of stat1-hdac4 confers resistance to etoposide through enhanced multidrug resistance 1 expression in human a549 lung cancer cells. Mol Med Rep 11(3): 2315-2321, 2015.

10 Mahal K, Schruefer S, Steinemann G, Rausch F, Schobert R, Biersack B and Hopfner M: Biological evaluation of 4,5diarylimidazoles with hydroxamic acid appendages as novel dual mode anticancer agents. Cancer Chemother Pharmacol 75(4): 691-700, 2015.

11 Wang L, Hou X, Fu H, Pan X, Xu W, Tang W and Fang H: Design, synthesis and preliminary bioactivity evaluations of substituted quinoline hydroxamic acid derivatives as novel histone deacetylase (hdac) inhibitors. Bioorg Med Chem 23(15): 4364-4374, 2015.

12 Wang $\mathrm{X}, \mathrm{Xu} \mathrm{J}$, Wang $\mathrm{H}$, Wu L, Yuan W, Du J and Cai S: Trichostatin a, a histone deacetylase inhibitor, reverses epithelial-mesenchymal transition in colorectal cancer sw480 and prostate cancer pc3 cells. Biochem Biophys Res Commun 456(1): 320-326, 2015.

13 Shen L, Orillion A and Pili R: Histone deacetylase inhibitors as immunomodulators in cancer therapeutics. Epigenomics 8(3): 415-428, 2016.
14 Gameiro SR, Malamas AS, Tsang KY, Ferrone S and Hodge JW: Inhibitors of histone deacetylase 1 reverse the immune evasion phenotype to enhance $\mathrm{t}$-cell mediated lysis of prostate and breast carcinoma cells. Oncotarget, 2016.

15 Helland O, Popa M, Bischof K, Gjertsen BT, McCormack E and Bjorge L: The hdaci panobinostat shows growth inhibition both in vitro and in a bioluminescent orthotopic surgical xenograft model of ovarian cancer. PLoS One 11(6): e0158208, 2016.

16 He W, Wu Y, Tang X, Xia Y, He G, Min Z, Li C, Xiong S, Shi $\mathrm{Z}, \mathrm{Lu} \mathrm{Y}$ and Yuan Z: Hdac inhibitors suppress c-jun/fra-1mediated proliferation through transcriptionally down-regulating mkk7 and raf1 in neuroblastoma cells. Oncotarget 7(6): 67276747,2016

17 He M, Qiao Z, Wang Y, Kuai Q, Li C, Jiang X, Wang X, Li W, Ren $\mathrm{S}$ and $\mathrm{Yu} \mathrm{Q}$ : Chidamide inhibits aerobic metabolism to induce pancreatic cancer cell growth arrest by promoting mcl-1 degradation. PLoS One 11(11): e0166896, 2016.

18 Chen MC, Huang HH, Lai CY, Lin YJ, Liou JP, Lai MJ, Li YH, Teng CM and Yang CR: Novel histone deacetylase inhibitor mpt0g009 induces cell apoptosis and synergistic anticancer activity with tumor necrosis factor-related apoptosis-inducing ligand against human hepatocellular carcinoma. Oncotarget 7(1): 402-417, 2016.

19 Han R, Sun Q, Wu J, Zheng P and Zhao G: Sodium butyrate upregulates mir-203 expression to exert anti-proliferation effect on colorectal cancer cells. Cell Physiol Biochem 39(5): 19191929, 2016.

20 Feng S, Yang Y, Lv J, Sun L and Liu M: Valproic acid exhibits different cell growth arrest effect in three hpv-positive/negative cervical cancer cells and possibly via inducing notch1 cleavage and e6 down-regulation. Int J Oncol 49(1): 422-430, 2016.

21 Murugan K, Sangeetha S, Ranjitha S, Vimala A, Al-Sohaibani S and Rameshkumar G: Hdacidb: A database for histone deacetylase inhibitors. Drug Des Devel Ther 9: 2257-2264, 2015.

22 Zhu L, Chiao CY, Enzer KG, Stankiewicz AJ, Faller DV and Dai Y: Sirt1 inactivation evokes antitumor activities in nsclc through the tumor suppressor p27. Mol Cancer Res 13(1): 41-49, 2015.

23 Liu J, Li Y, Dong F, Li L, Masuda T, Allen TD and Lobe CG: Trichostatin a suppresses lung adenocarcinoma development in grg1 overexpressing transgenic mice. Biochem Biophys Res Commun 463(4): 1230-1236, 2015.

24 De U, Kundu S, Patra N, Ahn MY, Ahn JH, Son JY, Yoon JH, Moon HR, Lee BM and Kim HS: A new histone deacetylase inhibitor, mhy219, inhibits the migration of human prostate cancer cells via hdac1. Biomol Ther (Seoul) 23(5): 434-441, 2015.

25 Zhang L, Zhang Y, Mehta A, Boufraqech M, Davis S, Wang J, Tian Z, Yu Z, Boxer MB, Kiefer JA, Copland JA, Smallridge RC, Li Z, Shen $M$ and Kebebew E: Dual inhibition of hdac and egfr signaling with cudc-101 induces potent suppression of tumor growth and metastasis in anaplastic thyroid cancer. Oncotarget, 2015.

26 Sakamoto T, Kobayashi S, Yamada D, Nagano H, Tomokuni A, Tomimaru Y, Noda T, Gotoh K, Asaoka T, Wada H, Kawamoto K, Marubashi S, Eguchi H, Doki Y and Mori M: A histone deacetylase inhibitor suppresses epithelial-mesenchymal transition and attenuates chemoresistance in biliary tract cancer. PLoS One 11(1): e0145985, 2016.

27 Ma J, Guo X, Zhang S, Liu H, Lu J, Dong Z, Liu K and Ming L: Trichostatin a, a histone deacetylase inhibitor, suppresses proliferation and promotes apoptosis of esophageal squamous cell lines. Mol Med Rep 11(6): 4525-4531, 2015. 
28 Wilson-Edell KA, Yevtushenko MA, Rothschild DE, Rogers AN and Benz CC: Mtorc1/c2 and pan-hdac inhibitors synergistically impair breast cancer growth by convergent akt and polysome inhibiting mechanisms. Breast Cancer Res Treat 144(2): 287 298, 2014

29 Datta J, Islam M, Dutta S, Roy S, Pan Q and Teknos TN: Suberoylanilide hydroxamic acid inhibits growth of head and neck cancer cell lines by reactivation of tumor suppressor micrornas. Oral Oncol 56: 32-39, 2016.

30 Wei W, Sun W, Yu S, Yang Y and Ai L: Butyrate production from high-fiber diet protects against lymphoma tumor. Leuk Lymphoma 57(10): 2401-2408, 2016.

31 Bultman SJ: Molecular pathways: Gene-environment interactions regulating dietary fiber induction of proliferation and apoptosis via butyrate for cancer prevention. Clin Cancer Res 20(4): 799803, 2014.

32 Wei W, Sun W, Yu S, Yang Y and Ai L: Butyrate production from high-fiber diet protects against lymphoma tumor. Leuk Lymphoma: 1-8, 2016.

33 Zhu B, Shang B, Li Y and Zhen Y: Inhibition of histone deacetylases by trans-cinnamic acid and its antitumor effect against colon cancer xenografts in athymic mice. Mol Med Rep 13(5): 4159-4166, 2016.

34 Evans SM, Casartelli A, Herreros E, Minnick DT, Day C, George E and Westmoreland C: Development of a high throughput in vitro toxicity screen predictive of high acute in vivo toxic potential. Toxicol In Vitro 15(4-5): 579-584, 2001.

35 Vlachos IS, Kostoulas N, Vergoulis T, Georgakilas G, Reczko M, Maragkakis M, Paraskevopoulou MD, Prionidis K, Dalamagas $\mathrm{T}$ and Hatzigeorgiou AG: Diana mirpath v.2.0: Investigating the combinatorial effect of micrornas in pathways. Nucleic Acids Res 40(Web Server issue): W498-504, 2012.

36 Wu CP, Hsiao SH, Su CY, Luo SY, Li YQ, Huang YH, Hsieh $\mathrm{CH}$ and Huang $\mathrm{CW}$ : Human atp-binding cassette transporters abcb1 and abcg 2 confer resistance to cudc-101, a multi-acting inhibitor of histone deacetylase, epidermal growth factor receptor and human epidermal growth factor receptor 2 . Biochem Pharmacol 92(4): 567-576, 2014.

37 Lee TG, Jeong EH, Kim SY, Kim HR and Kim CH: The combination of irreversible egfr tkis and saha induces apoptosis and autophagy-mediated cell death to overcome acquired resistance in egfr $\mathrm{t} 790 \mathrm{~m}$-mutated lung cancer. Int $\mathrm{J}$ Cancer 136(11): 2717-2729, 2015.

38 Wang L, Li H, Ren Y, Zou S, Fang W, Jiang X, Jia L, Li M, Liu $X$, Yuan X, Chen G, Yang J and Wu C: Targeting hdac with a novel inhibitor effectively reverses paclitaxel resistance in nonsmall cell lung cancer via multiple mechanisms. Cell Death Dis 7: e2063, 2016.
39 Masuoka Y, Shindoh N and Inamura N: Histone deacetylase inhibitors from microorganisms: The astellas experience. Prog Drug Res 66: 335, 337-359, 2008.

40 Shindoh N, Mori M, Terada Y, Oda K, Amino N, Kita A, Taniguchi M, Sohda KY, Nagai K, Sowa Y, Masuoka Y, Orita M, Sasamata M, Matsushime H, Furuichi K and Sakai T: Ym753, a novel histone deacetylase inhibitor, exhibits antitumor activity with selective, sustained accumulation of acetylated histones in tumors in the widr xenograft model. Int $\mathbf{J}$ Oncol 32(3): 545-555, 2008.

41 Katiyar SK: Dietary proanthocyanidins inhibit uv radiationinduced skin tumor development through functional activation of the immune system. Mol Nutr Food Res, 2016.

42 Tong LX and Young LC: Nutrition: The future of melanoma prevention? J Am Acad Dermatol 71(1): 151-160, 2014.

43 Afaq F and Katiyar SK: Polyphenols: Skin photoprotection and inhibition of photocarcinogenesis. Mini Rev Med Chem 11(14): 1200-1215, 2011.

44 Singh RP, Tyagi AK, Dhanalakshmi S, Agarwal R and Agarwal C: Grape seed extract inhibits advanced human prostate tumor growth and angiogenesis and upregulates insulin-like growth factor binding protein-3. Int J Cancer 108(5): 733-740, 2004.

45 Walter RB, Brasky TM, Milano F and White E: Vitamin, mineral, and specialty supplements and risk of hematologic malignancies in the prospective vitamins and lifestyle (vital) study. Cancer Epidemiol Biomarkers Prev 20(10): 2298-2308, 2011.

46 Brasky TM, Kristal AR, Navarro SL, Lampe JW, Peters U, Patterson RE and White E: Specialty supplements and prostate cancer risk in the vitamins and lifestyle (vital) cohort. Nutr Cancer 63(4): 573-582, 2011.

47 Kong AN, Zhang C and Su ZY: Targeting epigenetics for cancer prevention by dietary cancer preventive compounds--the case of mirna. Cancer Prev Res (Phila) 6(7): 622-624, 2013.

48 Vaid M, Prasad R, Singh T, Jones V and Katiyar SK: Grape seed proanthocyanidins reactivate silenced tumor suppressor genes in human skin cancer cells by targeting epigenetic regulators. Toxicol Appl Pharmacol 263(1): 122-130, 2012.
Received October 14, 2016

Revised December 8, 2016

Accepted December 9, 2016 